\title{
Research Paper \\ The effectiveness of combination therapy of acceptance and commitment therapy and theraplay on severity of symptoms and function of children with obsessive-compulsive disorder
}

\footnotetext{
Saiede Safari ${ }^{1}$, Mehrdad Kalantari ${ }^{2}$, Fariba Yazdkhasti ${ }^{3}$, MohammadReza Abedi ${ }^{4}$, HamidReza Oreyzi $^{2}$

1.Ph.D Student in Psychology, Department of Psychology, Faculty of Education and Psychology, University of Isfahan, Isfahan, Iran.

2. Professor, Department of Psychology, Faculty of Education and Psychology, University of Isfahan, Isfahan, Iran.

3. Associate Professor, Department of Psychology, Faculty of Education and Psychology, University of Isfahan, Isfahan, Iran.

4. Professor, Department of Counseling, Faculty of Education and Psychology, University of Isfahan, Isfahan, Iran.
}

Citation: Safari S, Kalantari M, Yazdkhasti F, Abedi M.R, Oreyzi H.R. The effectiveness of combination therapy of acceptance and commitment therapy and theraplay on severity of symptoms and function of children with obsessive-compulsive disorder. $\mathrm{J}$ of Psychological Science. 2021; 20(105): 1535-1552.

URL: https://psychologicalscience.ir/article-1-960-fa.html
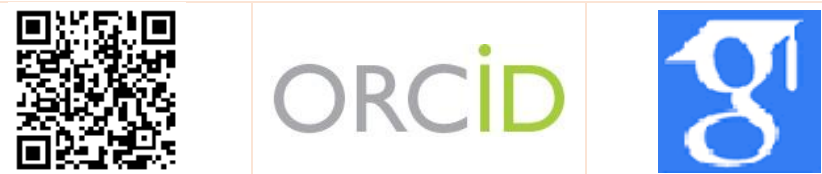

\section{$10.52547 / J P S .20 .105 .1535$}

\section{A R T I C L E I N F O A B S T R A C T}

Keywords:

Obsessive - Compulsive

Disorder,

Acceptance and

Commitment Therapy,

Theraplay,

Performance,

Child

Received: 15 Sep 2020

Accepted: 10 Oct 2020

Available: 22 Nov 2021
Background: Several studies have examined the effectiveness of Acceptance and Commitment Therapy on the severity of obsessive-compulsive disorder symptoms. But research that examines the effectiveness of this treatment in combination with Theraplay on the symptoms and function of children with obsessive-compulsive disorder has been neglected.

Aims: The present study investigates the effectiveness of combination therapy of Acceptance and Commitment Therapy and Theraplay on the symptoms and Function of children with obsessivecompulsive disorder.

Methods: This was a quasi-experimental study with pre-test and post-test with 3-month follow-up and control group. The statistical population of the study included all children with obsessivecompulsive disorder aged 8 to 12 years in Esfahan in 2019, along with their mothers at the time of the study, of which 20 children with their parents, after an authentic psychiatrist or psychologist diagnosed them with obsessive-compulsive disorder and they obtained at least a score of 14 on the Children's Yale-Brown OC Scale, were selected based on Purposive sampling method and randomly assigned into the experimental and control groups. The experimental group received the combination therapy of Acceptance and Commitment Therapy and Theraplay for 10 sessions of individual counseling, but the control group did not receive any intervention. Instruments used in the study included Children's Yale-Brown OC Scale(CY-BOCS), Child Obsessive Compulsive Impact Scale - Revised(COIS-R / P) and Marschak Interaction Method Behavior Rating System.

Results: To analyze the findings, inferential statistics methods of analysis of repeated measures were used. The findings of this study confirmed the effect of combination therapy of Acceptance and Commitment Therapy and Theraplay on reducing the symptoms of obsessive-compulsive disorder, improvement overall performance and the improvement of academic, social, family and daily livng skills performance $(\mathrm{P}<0 / 05)$.

Conclusion: The combination therapy of Acceptance and Commitment Therapy and Theraplay is effective to reduce symptoms and improve Function in children with obsessive-compulsive disorder.

* Corresponding Author: Mehrdad Kalantari, Professor, Department of Psychology, Faculty of Education and Psychology, University of Isfahan, Isfahan, Iran.

E-mail: mehrdadk@edu.ui.ac.ir

Tel: (+98) 9131151529

2476-5740/ (C) 2021 The Authors. This is an open access article under the CC BY-NC-ND license

(https://creativecommons.org/licenses/by-nc/4.0/). 


\section{Extended Abstract}

\section{Introduction}

Obsessive-compulsive disorder in children is a debilitating mental disorder that can affect a child's life into adulthood. This disorder includes disturbing, unwanted, and repetitive thoughts that the child finds unpleasant and frightening. He/she cannot deal effectively with the compulsion of obsessive actions and resort to the actions to get rid of anxiety (Krebs \& Heyman, 2015). Quality of life of children with obsessive-compulsive disorder as well as their family members can be limiting and challenging (Nazer, Latif, Mondal, Azeem \& Greydanus, 2020) and associated with disruption in family functionality, relationships with friends and academic performance (Brezinka., Mailänder., \& Walitza, 2020).

Research evidence suggests that acceptance and commitment therapy is a new approach in the treatment of obsessive-compulsive disorder (Barney, Field, Morrison \& Twohig, 2017). In Armstrong, Morrison \& Twohig (2013), three adolescents with obsessive-compulsive disorder underwent between eight and ten sessions of acceptance and commitment therapy, and their parents entered the room at the final moments of the sessions. Initial results showed that immediately after treatment, the rate of obsessivecompulsive symptoms was reduced to $28 \%$ and in a three-month follow-up to $42 \%$. In addition, all participants considered this treatment acceptable.

It is undeniable that in addition to the psychological flexibility emphasized in the acceptance and commitment approach, many deeper psychological aspects of parent-child relationships can also contribute in children's disorders. One of the most important of them is parent-child attachment (Van Leeuwena, van Wingena, Luytenbc, Denysa, \& van Marleade 2020). So that the levels of insecure attachment are strongly associated with the symptoms of obsessive-compulsive disorder in children and predict a high percentage of variability in the symptoms of the disorder (Goli, Abd Khodaei, Mashhadi and Bigdeli, 2020; Rezvan et al., 2013; Myhr, Sookman \& Pinard, 2004).

Attachment Centered Play Therapy is a focused, relatively short-term approach that actively engages parents in their child's therapy sessions to create coordination and adaptation in the parent-child relationship. The goal of this approach is to increase attachment, self-regulation, trust, and enjoyable interaction, and to enable parents to continue the healthy interactions they learned during treatment sessions on their own after treatment. Therefore, due to the strong relationship between insecure attachment and obsessive-compulsive disorder, it is necessary to integrate attachment-based and cognitive treatment approaches for patients whose emotional and developmental factors prevent their successful treatment (Van Leeuwena, et al., 2020).

Therefore, considering the psychological and emotional damages in children with obsessivecompulsive disorder and the importance of using appropriate therapies and interventions, the present study aimed to investigate the effectiveness of combination of acceptance and commitment therapy and Attachment Centered Play Therapy on symptoms and performance of children with obsessivecompulsive disorder.

\section{Method}

The present study is a applied research based on a quasi-experimental model with pre-test/post-test, control group and 3-month follow-up design. The statistical population of the study included all children with obsessive-compulsive disorder between 8 and 12 years old in Esfahan in city 2019, along with their mothers at the time of the study. The sample consisted of 20 children from the mentioned community who were selected based on purposive sampling which were randomly assigned into an experimental $(n=10)$ and a control group $(n=10)$. In both groups, a measurement package (which included research tools) was implemented. The experimental group was then received the intervention. At this stage, the control group did not receive any intervention. After 10 sessions of therapeutic intervention for the experimental groups, post-test was conducted for both (experimental and control) groups and 3 months after the end of the treatment intervention sessions, the subjects in both the experimental and control groups completed the questionnaires once again to assess the follow-up stage. The instruments used in the study included 


\section{Monthly Journal of Psychological Science}

Children's Yale-Brown Obsessive Compulsive Scale (CY-BOCS1) and Child Obsessive-Compulsive Impact Scale-Revised, Parent-Version (COIS-R/P). The combined intervention of acceptance and commitment therapy and Attachment Centered Play Therapy was reviewed and approved by the researcher, and its content was corrected by several experts in this field. It was performed in ten 60minute sessions on a weekly basis. Analysis of variance mixed with repeated measures was used to analyze the data using SPSS22 software.

\section{Results}

Among the 20 children participating in the study, 8 were boys (experiments: 3, control: 5) and 12 girls

Table 1. ANOVA with repeated measure(The effect of combination therapy on the performance and symptoms of children with obsessivecompulsive disorder)

\begin{tabular}{|c|c|c|c|c|c|c|c|c|c|}
\hline & source & f variation & $\begin{array}{l}\text { sums of } \\
\text { squares }\end{array}$ & df & $\begin{array}{c}\text { mean } \\
\text { squares }\end{array}$ & $\mathrm{F}$ & significant & $\begin{array}{c}\text { Eta } \\
\text { squared }\end{array}$ & $\begin{array}{l}\text { statistica } \\
\text { l power }\end{array}$ \\
\hline \multirow{3}{*}{$\begin{array}{l}\text { Performance associated } \\
\text { with obsessive- } \\
\text { compulsive disorder }\end{array}$} & \multirow{2}{*}{ Intragroup } & Time & 1202.633 & 1.130 & 1064.608 & 94.092 & 0.0001 & 0.839 & 1 \\
\hline & & Time + Group & 1509.300 & 1.130 & 1336.078 & 118.085 & 0.0001 & 0.869 & 1 \\
\hline & Intergroup & Group & 2982.150 & 1 & 2982.150 & 12.203 & 0.003 & 0.404 & 0.910 \\
\hline \multirow{3}{*}{ Academic Performance } & \multirow{2}{*}{ Intragroup } & Time & 69.233 & 1.294 & 53.505 & 37.016 & 0.0001 & 0.673 & 1 \\
\hline & & Time + Group & 60.433 & 1.294 & 46.704 & 32.311 & 0.0001 & 0.642 & 1 \\
\hline & Intergroup & Group & 112.067 & 1 & 112.067 & 9.008 & 0.008 & 0.334 & 0.810 \\
\hline \multirow{3}{*}{ Family function } & \multirow{2}{*}{ Intragroup } & Time & 47.50 & 1.188 & 39.976 & 20.786 & 0.0001 & 0.536 & 0.996 \\
\hline & & Time + Group & 88.033 & 1.188 & 74.089 & 38.524 & 0.0001 & 0.682 & 1 \\
\hline & Intergroup & Group & 190.817 & 1 & 190.817 & 4.547 & 0.047 & 0.202 & 0.523 \\
\hline \multirow{3}{*}{ Social Performance } & \multirow{2}{*}{ Intragroup } & Time & 230.533 & 1.080 & 213.358 & 73.401 & 0.0001 & 0.803 & 1 \\
\hline & & Time + Group & 268.933 & 1.080 & 284.898 & 85.627 & 0.0001 & 0.826 & 1 \\
\hline & Intergroup & Group & 493.067 & 1 & 493.067 & 0.042 & 0.0001 & 0.211 & 0.545 \\
\hline \multirow{3}{*}{ Everyday life skills } & \multirow{2}{*}{ Intragroup } & Time & 18.433 & 1.348 & 13.672 & 13.132 & 0.0001 & 0.422 & 0.972 \\
\hline & & Time + Group & 29.633 & 1.348 & 21.979 & 21.111 & 0.0001 & 0.540 & 0.998 \\
\hline & Intergroup & Group & 64.067 & 1 & 64.067 & 4.835 & 0.041 & 0.212 & 0.548 \\
\hline \multirow{3}{*}{$\begin{array}{c}\text { The total score of } \\
\text { obsession }\end{array}$} & \multirow{2}{*}{ Intragroup } & Time & 1202.633 & 1.130 & 1064.608 & 94.092 & 0.0001 & 0.839 & 1 \\
\hline & & Time + Group & 1509.300 & 1.130 & 1336.078 & 118.085 & 0.0001 & 0.868 & 1 \\
\hline & Intergroup & Group & 2982.150 & 1 & 2982.150 & 12.203 & 0.003 & 0.404 & 0.910 \\
\hline
\end{tabular}

\section{Conclusion}

During combination therapy of Acceptance and Commitment Therapy and Theraplay parents guide to adapt to their child's needs and moods. And respond directly to the basic needs of the child, which leads to a reduction in psychological disorders by creating psychological flexibility in parents and children (Petts, Duenas, Gaynor, 2017). Also, combination therapy in the process of creating mutual attachment between parent and child leads to improved interpersonal interactions and improves the quality of (experiments: 7, controls: 5). The mean age of children in the experimental group was 10.01 and in the control group was 9.90. The results of t-test showed no difference between the two groups in the age variable $(t=-0.189, \mathrm{Sig}=0.762)$. Table 1 shows the mean and standard deviation of pre-test, post-test and Follow up of performance and symptoms of children with obsessive-compulsive disorder.

in the table 1 examines the effect of combination therapy on the performance and symptoms of children with obsessive-compulsive disorder.

life of the child(Glibota, Lindaman \& Coleman, 2018). This treatment reduces the symptoms of the disorder by not paying direct attention to the symptoms of the disorder and simply by emphasizing the cognitive ability in the child and the two-way relationship with the parent(Van Leeuwena \& et al, 2020). combination therapy of Acceptance and Commitment Therapy and Theraplay has a direct effect on the relationship between parent and child and helps the quality of the child's performance by reducing the symptoms of the disorder(Tompson, 
Langer, Hughes, \& Asarnow, 2017). Limited scope of research to children with obsessive-compulsive disorder in Isfahan and the existence of some uncontrolled variables such as financial status of families, number of children, their social status, intelligence status of children in the study and not using random sampling methods were the limitations of this study.

\section{Ethical Considerations}

Compliance with ethical guidelines: This study obtained its ethical approval from the University of Isfahan (Code: IR.UI.REC.1399.047). Participants were assured of the confidentiality of their information. The purpose of study was explained to them and signed a written consent form. They were also assured that there was no need to enter a name and that the results of the study would be reported at the general level to be provided to psychologists and psychiatrists to advance therapeutic goals.

Funding: This research was extracted from the $\mathrm{PhD}$. thesis of first author approved by the Department of Education and Psychology, University of Isfahan in Isfahan, Iran.

Authors' contribution: Conceptualization and investigation: All authors; Methodology, validation, data analysis: Mohammad reza abedi, Hamidreza oreizi, Siede safari; editing, project administration: Mehrdad kalantari, Fariba yazdekhasti, Saiede safari;Translation of the scale and interpretation: Saiede safari; writing \& review: Saiede safari.

Conflict of interest: The author declared no conflict of interest. Acknowledgments: We want to express our gratitude towards all the study participants without whom conducting this research would not have been possible. 


\section{كود كان مبتلا به اختلال وسواس - ناخوددارى}

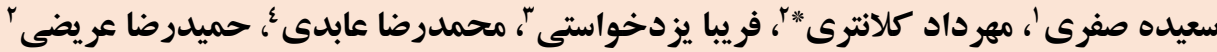

ا. دانشجوى دكترى روانشناسى، گروه روانشناسى، دانشكده علومتربيتى و روانشناسى، دانشكاه اصفهان، اصفهان، ايران.

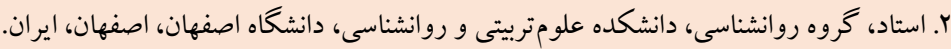

r.

F. أ. استاد، كروه مشاوره، دانشكده علوم تربيتى و روانشناسى، دانشكاه اصفهان، اصفهان، ايران.

\section{جكيله}

زمينه: جند مطالعه به بررسى اثربخشى درمان مبتى بر يذّيرش و تعهل بر شدت نشانهاى اختلال وسواس يرداختهاند؛ اما يُزوهشى كه به

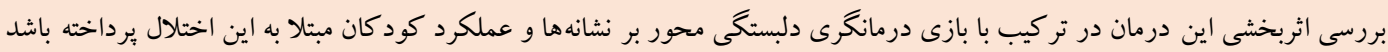
مغفول مانده است. هدف: يزوهش حاضر به بررسى اثربخشى درمان تركيبى يذيرش و تعهد و بازىدرمانگرى دلبستگى محور بر علائم و عملكرد كود كان مبتلا به اختلال وسواس - ناخوددارى مى يردازد.

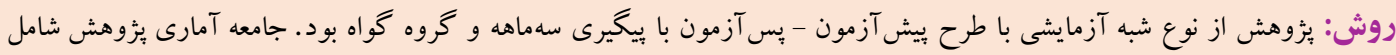

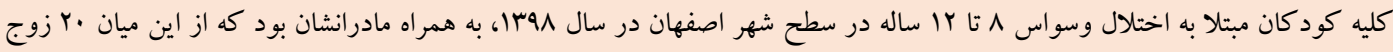
كودك و مادر يس از تشخيص روانيزشك يا روانشناس معتبر، به اختلال وسواس و كسب حداقل نمره: fأ در مقياس وسواس جبرى ييل

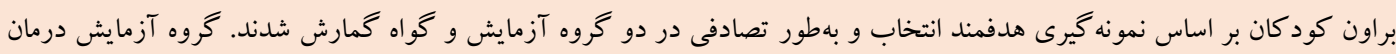

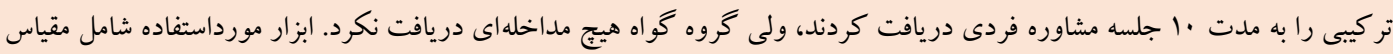

وسواس - ناخوددارى ييل براون كود كان (CY-BOCS) و مقياس تأثير وسواس در كودك - نسخة والدين (COIS- R/ P) بود. يافته ها: براى تحليل دادها از روش تحليل واريانس آميخته با اندازهيرى مكرر استفاده شد. يافتهاى اين يُووهش، تأثير درمان تركيبى

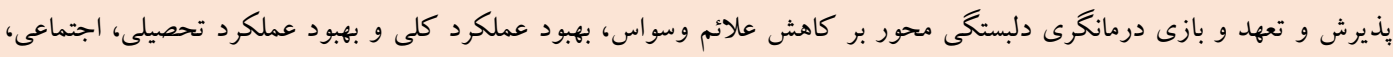

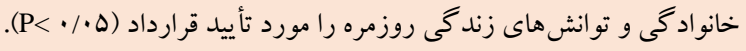

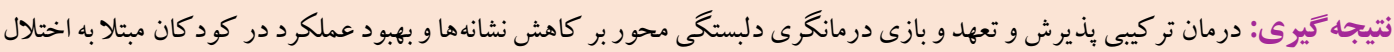
وسواس - ناخوددارى اثربخش است.
مشخصات مقاله

كليدوازهها: - مها:

اختلال وسواس - ناخوددارى، إن درمان مبتى بر يذيرش و تعهد،

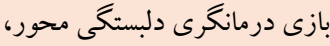
عملكرد، باكن. كودك

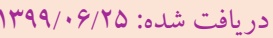
يذيرفته شده:

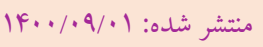

* نويسنده مسئول: مهرداد كلانترى، استاد، گروه روانشناسى، دانشكده علومتربيتى و روانشناسى، دانشكاه اصفهان، اصفهان، ايران. رايانه: mehrdadk@edu.ui.ac.ir 
ييشينه بالينى مربوط به درمان اختلال وسواس حاكى از آن است كه علاوه

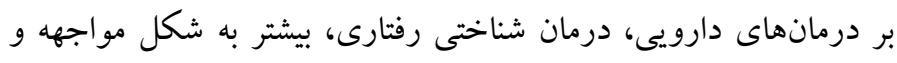

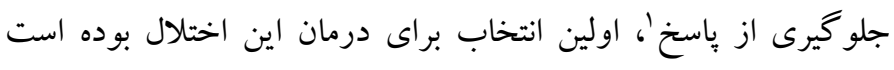

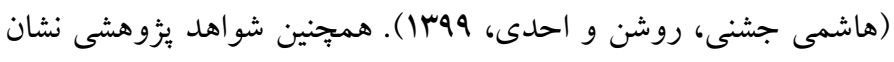

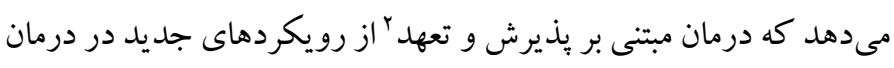

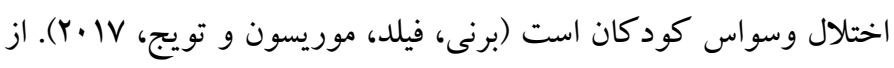
اين ديدگاه، اختلال وسواس - ناخوددارى نشاندهنده انعطافنايذيرى

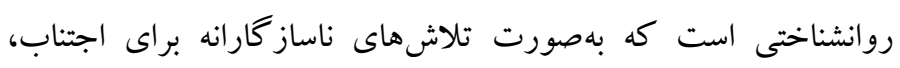
اصلاح و كنترل شناخت ها و اضطر اب مرتبط با وسواسها صورت مى بذيرد

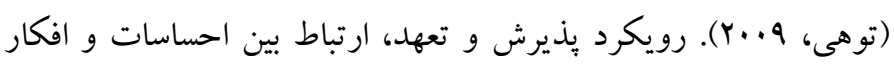

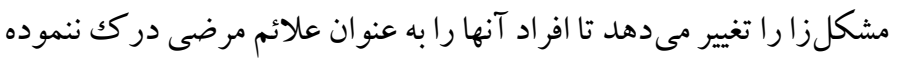

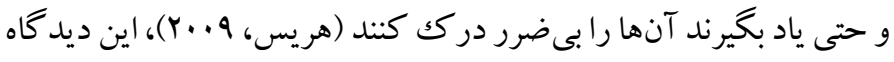
تمركز كمترى بر روى نشانها دارد و بيشتر متمركز بر افزايش كيفيت إنها

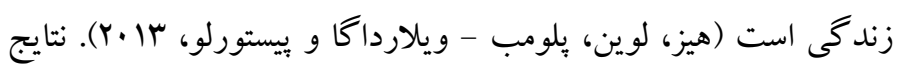

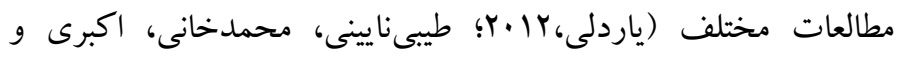

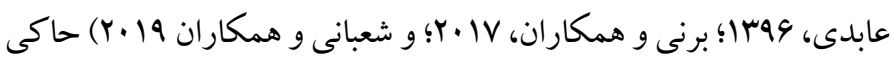
از اثربخش بودن درمان مبتنى بر بذيرش و تعهل بر كاهش نشانكان اختلال

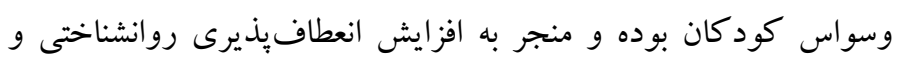

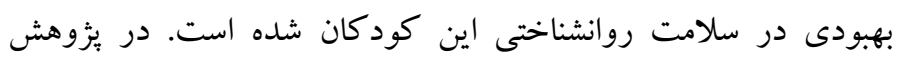

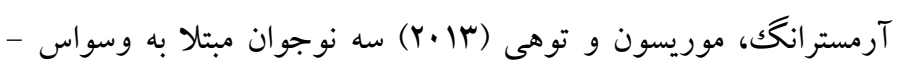

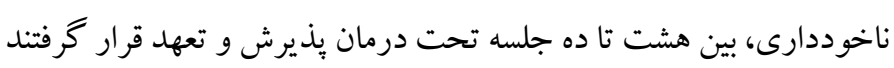

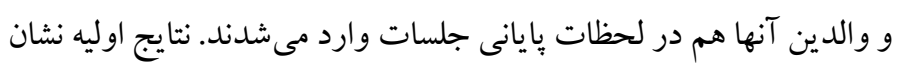

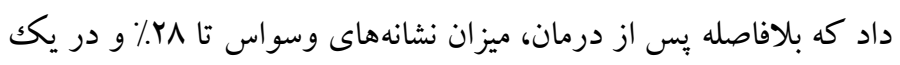

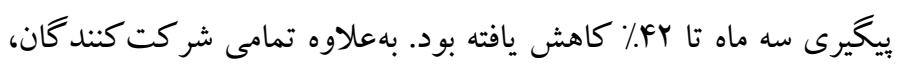

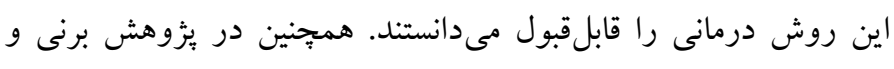

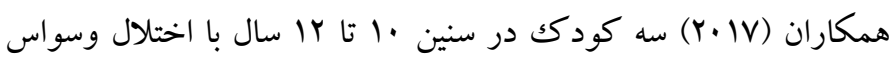
فكرى عملى همراه با والدينشان كه در كل جلسات حضور داشتند تحت درمان مبتنى بر بذيرش و تعهد قرار گرفتند، درمان توسط مشاور مدر مدرسه

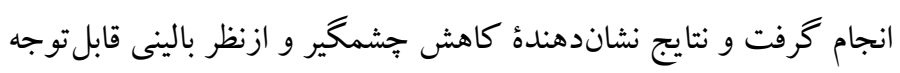
اختلال وسواس در بين شركت كنند كان بود.

2 . Acceptance andcommitment therapy
مقدمله

وسواس - ناخوددارى، در كود كان يكك اختلال روانى ناتوان كننده است

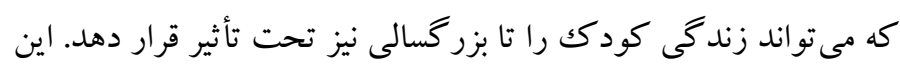

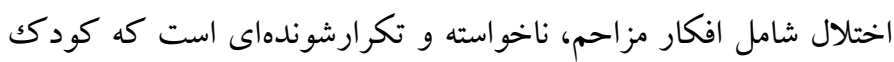
آنها را ناخوشايند و ترسناك قلمداد مى كند، نمى تواند در مقابل جبر اعمال

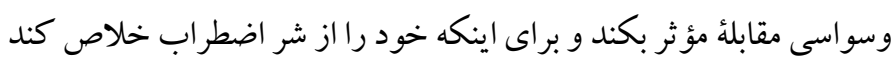

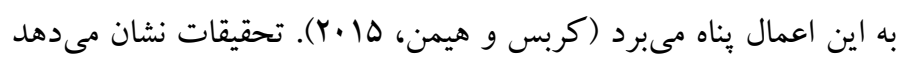

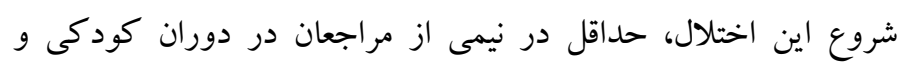

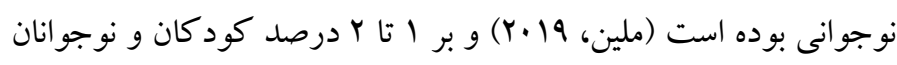

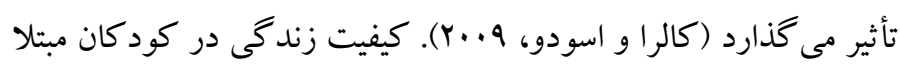

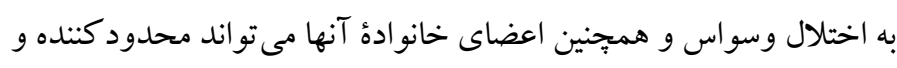

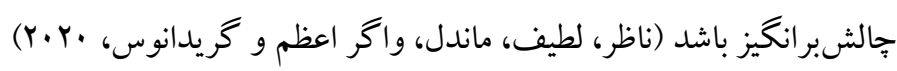

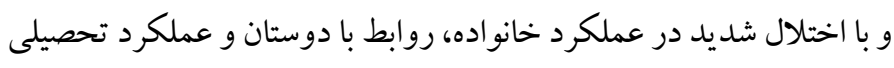

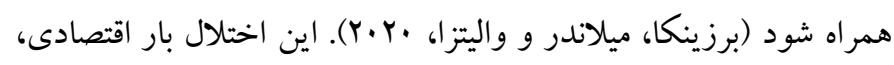

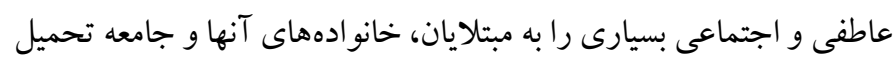

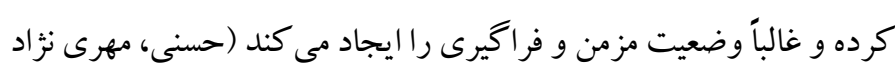

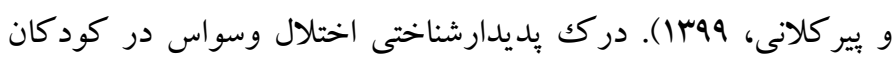

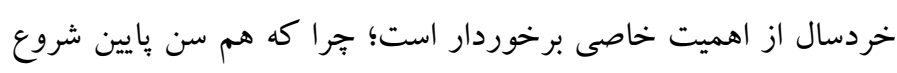

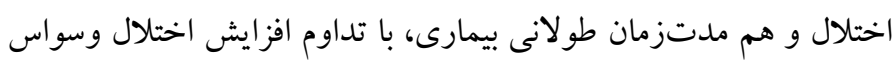

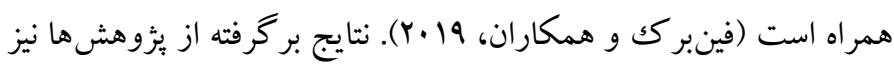

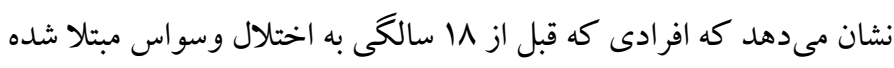
بودند بيشرفت آموزشى ضعيف ترى را در همه سطوح آموزشى نشان دادند

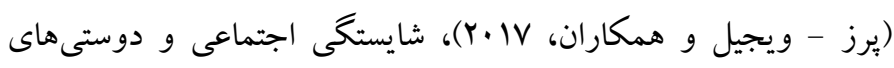

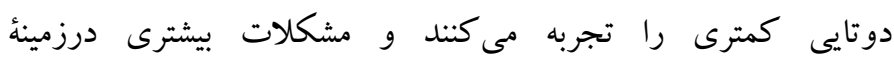

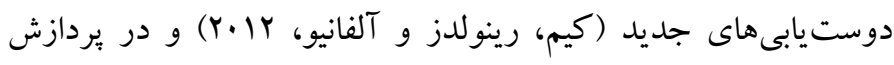

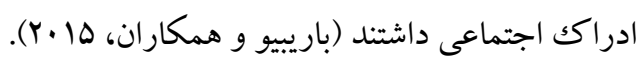
وسواس در كودكان، علىرغم داشتن سيرى بسيار ناتوانكنده و تأثير

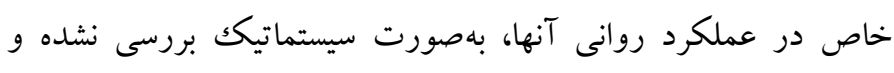

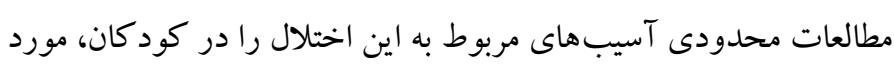

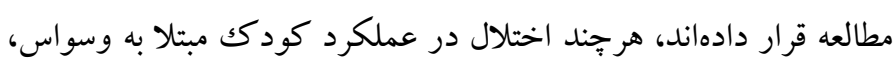
اغلب، دليلى براى جستو جوى درمان بوده است (ندئو و همكاران، با ·Y).

${ }^{1}$. exposure-response prevention (ERP) 
از نقش دلبستخى در نشانهاى اختلال وسواس حاصل تحقيقاتى است كه

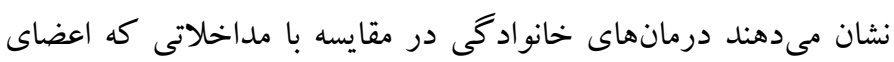

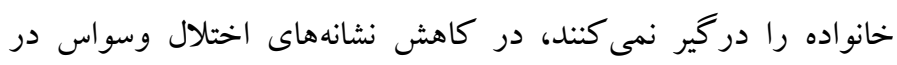

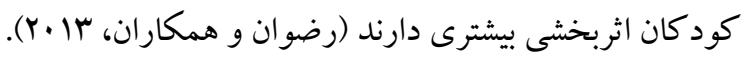

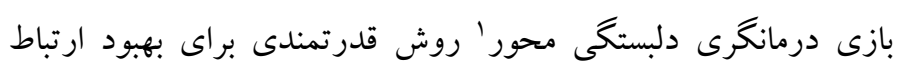

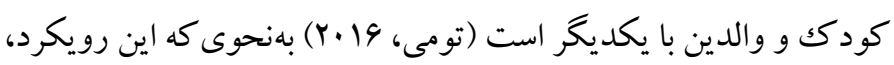

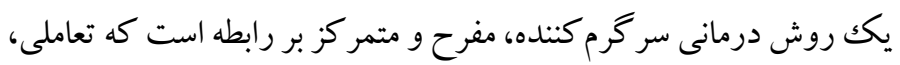

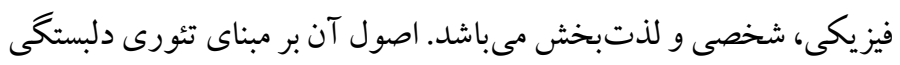

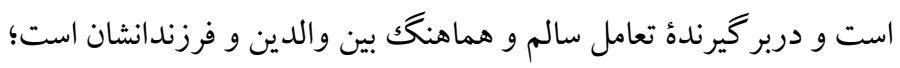

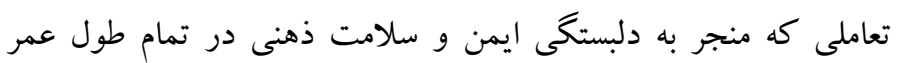

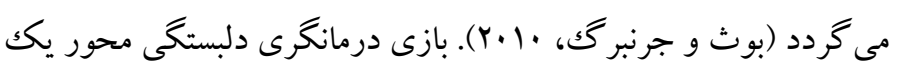

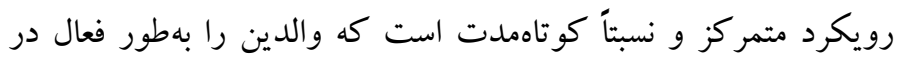

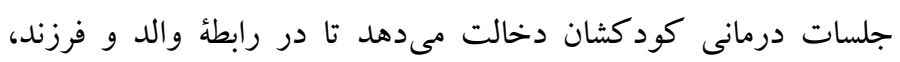

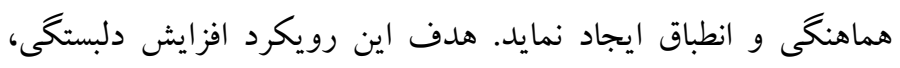
خودتنظيمى، اعتماد و تعامل لذتبخش مئ باشد و والدين را توانمند

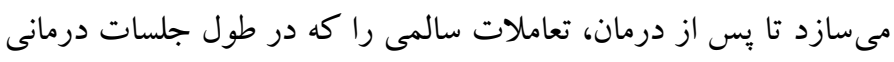
فراگرفته بودند به تنهايى ادامه دهند. ازاينرو با توجه به رابطه قوى بـ بين

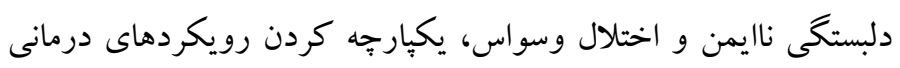
مبتنى بر دلبستكى و شناختى براى بيمارانى كه عوامل عاطفى و رشدى مانع

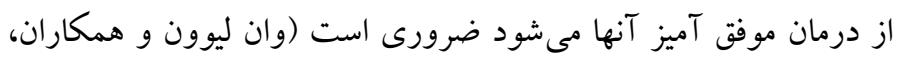

(Y.Y.

كودكان مبتلا به اختلالهاى روانشناختى مانند اختلال وسواس، نياز به

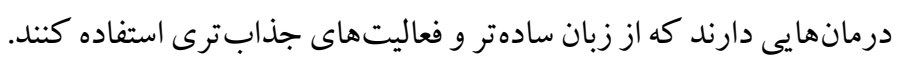

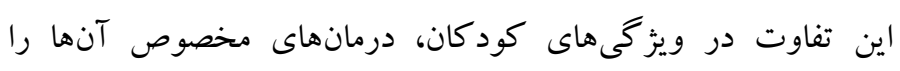

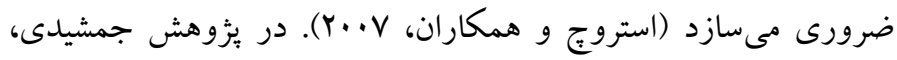

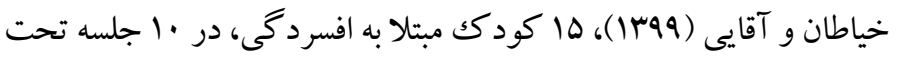
درمان تركيبى يذيرش و تعهد و بازى درمانگرى دلبستخى محور قرار

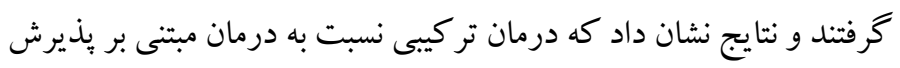

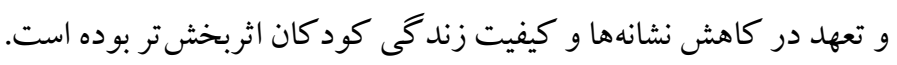

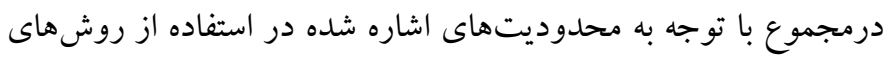
درمانى رايج، مانند درمانهاى شناختى - رفتارى، دارودرمانى و درمان
درگير شدن خانواده در فر آيند درمانى كودكان و رهايى خود والدين از

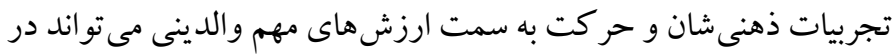

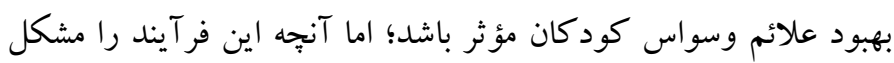

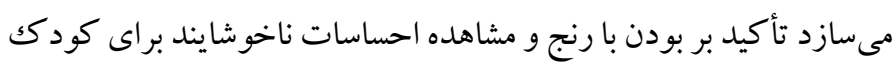

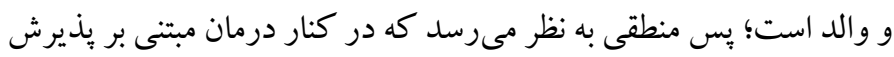
و تعهد درمان ديخرى نياز باشد كه فرآيند يذيرش تجربيات ذهنى را بهر

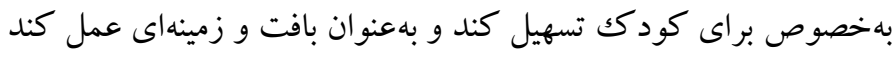

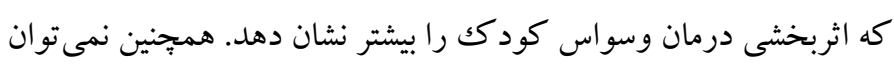

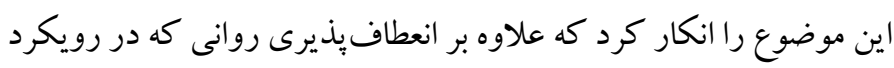

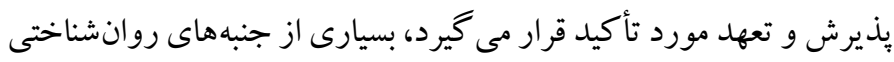

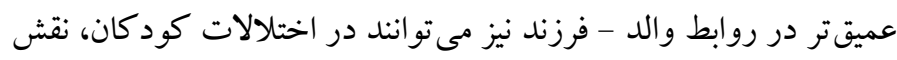

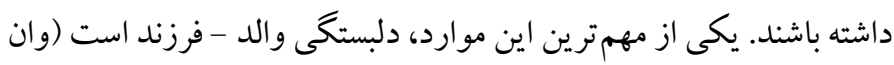

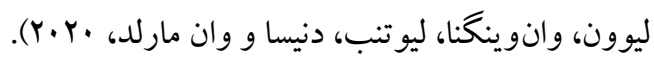

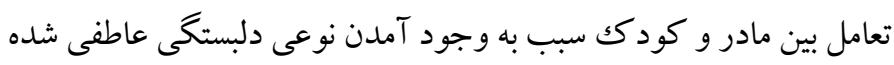

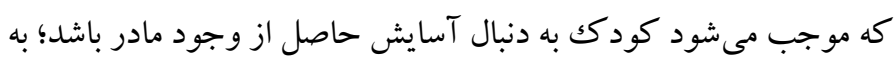

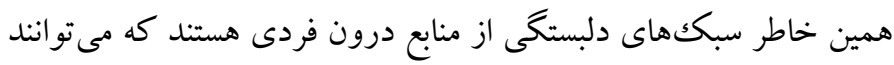

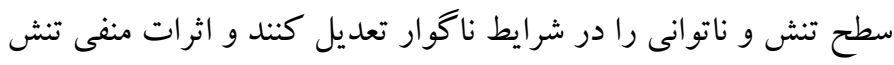

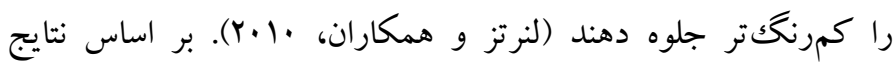

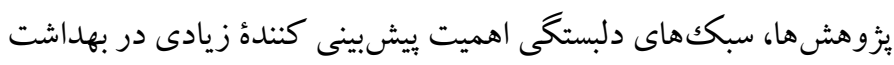

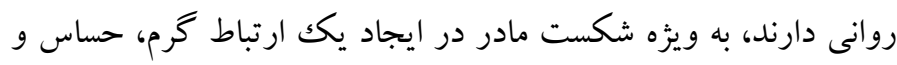

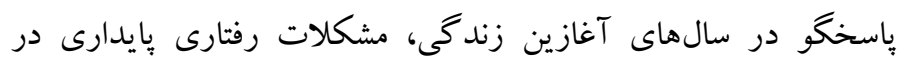

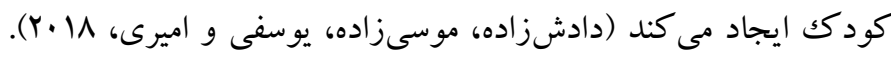

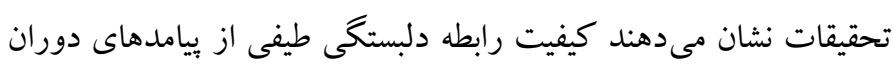
كودكى ازجمله اختلال وسواس را ييشبينى مى كند (دورن و همكاران،

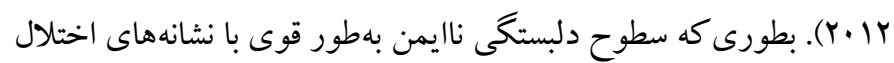

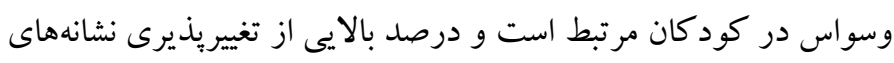

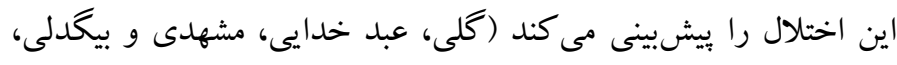

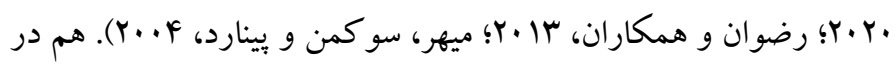

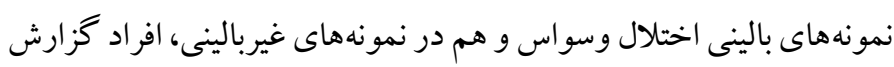

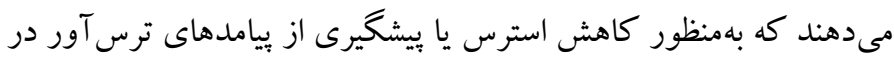

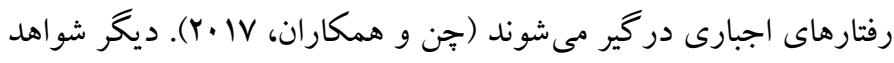

${ }^{1}$. Theraplay 
اين مراكز، از آنان خواسته شد در صورت تمايل به همكارى در اين طرح

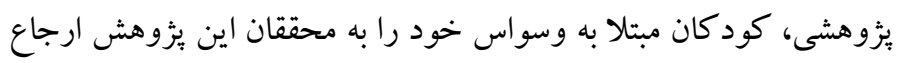

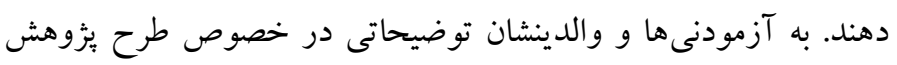

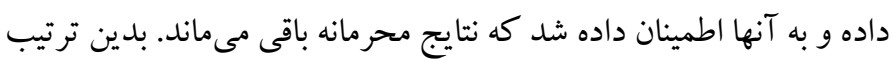

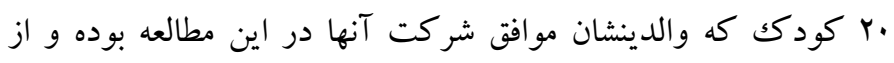
ملاكك هاى ورود برخوردار بودند. ملاكك ورود آزمودنىها به اين يُزوهش شامل اين موارد بود: (1) قرار

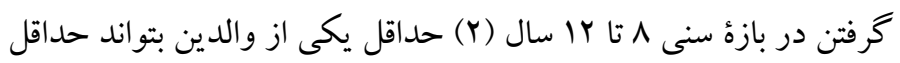
در •^ درصد از جلسات درمان، همراه با كود كانشان حضور بيدا كند

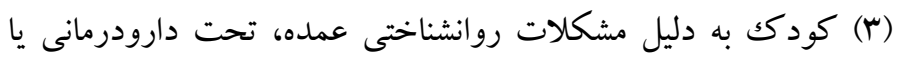
رواندرمانى نباشد و كود كك عقبمانده ذهنى نباشد (F) كسب حداقل نمره If در مقياس وسواس جبرى ييل براون كودكان بس از تشخيص روان بزشك يا روانشناس معتبر به اختلال وسواس)، رضايتنامة كتبى را تكميل

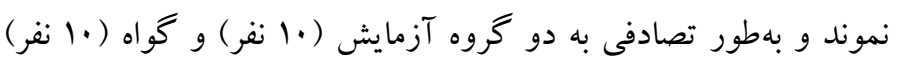

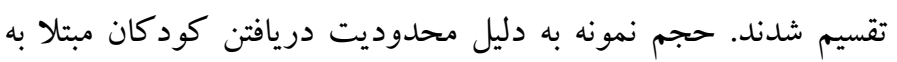

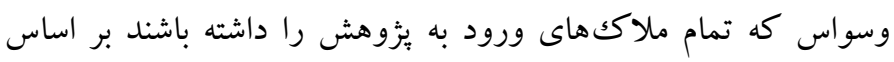
حداقل حجم نمونه در مطالعات آزمايشى انتخاب شد (كويين و كيگك،

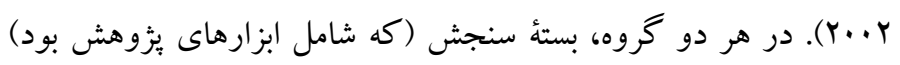

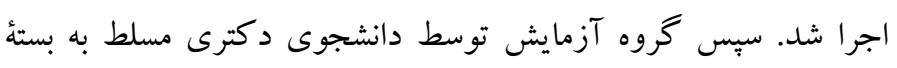

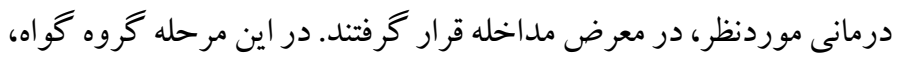

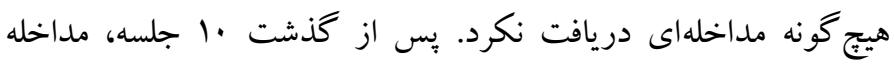

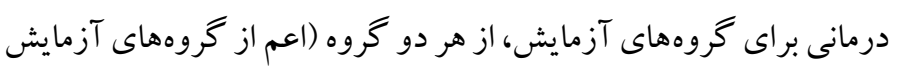

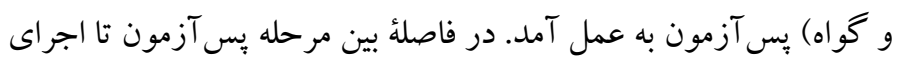

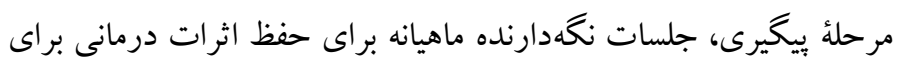

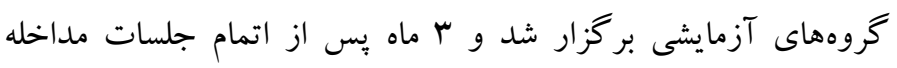

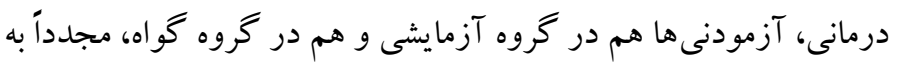
تكميل برسشنامهها جهت سنجش مرحله بيخيرى اقدام نمودند. مداخله

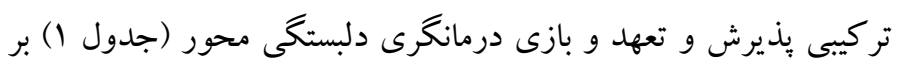

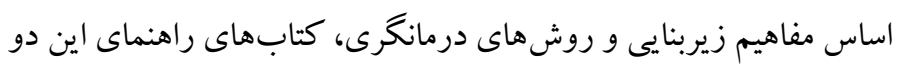

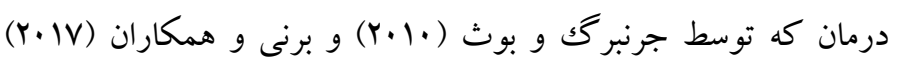
تدوينشده بود، يس از بررسى مبانى نظرى و ئزوهشهاى مرتبط

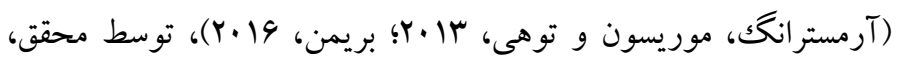

مبتنى بر يذيرش و تعهد در درمان اختلال وسواس كودكان، به كاركيرى

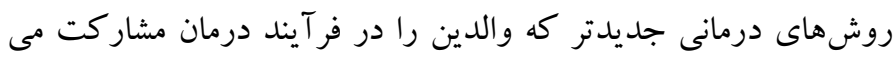

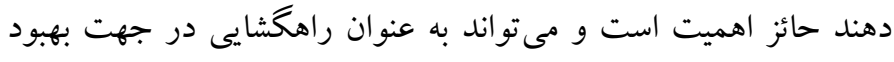
مؤلفهاى روانشناختى اين كود كان به شمار رود. همجينين ئزوهشهاى انجام شده در حيطه اختلال وسواس كود كان، مخصوصاً در جامعه ايران بسيار اندك است، كمبود مطالعات مربوط به مداخلات روانشناختى بر

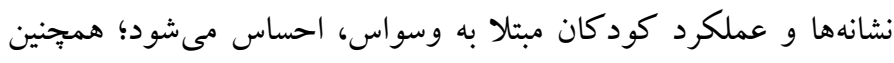
از آنجايى كه وسواس يكك اختلال ناتوان كننده است و سبب ايجاد اختلال

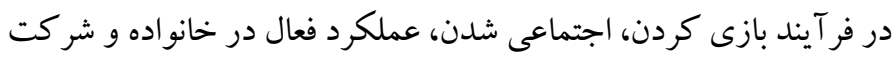

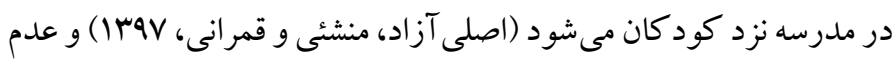
درمان اين اختلال در سنين كودكى مى تواند منجر به بروز آسيبهاى بيشتر

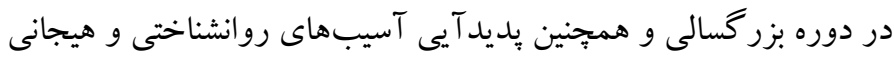

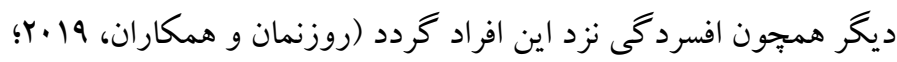

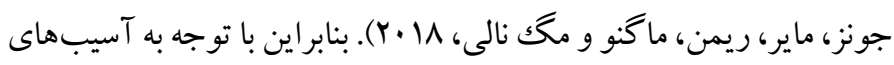

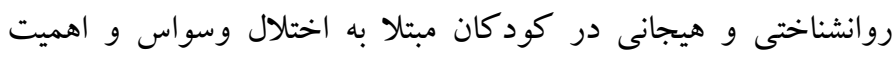

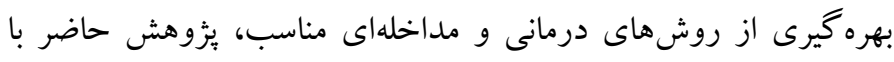

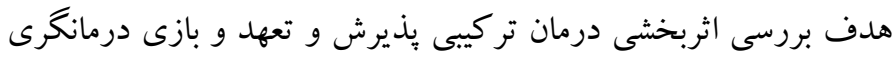

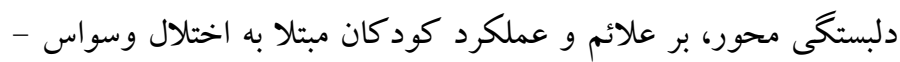
ناخو ددارى اجراشده است.

روش الف) طرح :ثزوهش و شر كت كنند تان: بزوهش حاضر بهنظور تعيين

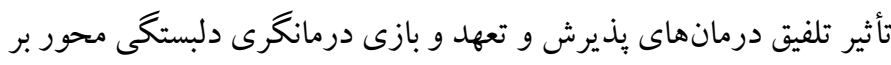

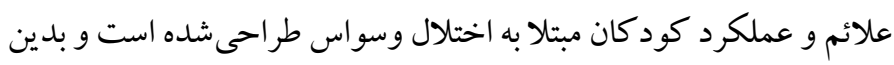
ترتيب يكك بثزوهش كاربردى بوده و مبتنى بر الكوى شبه تجربى با عنوان

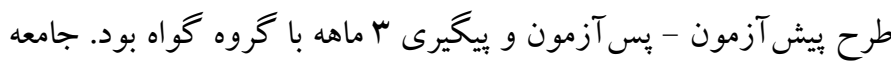
آمارى يُزوهش شامل كليه كود كان مبتلا به اختلال وسواس - ناخوددارى

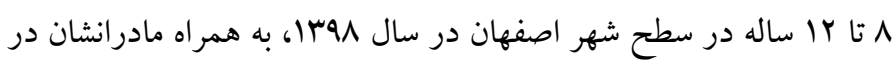

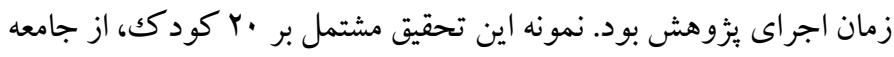

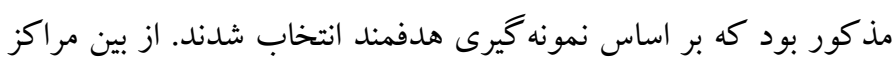

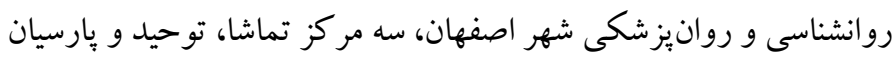
بهصورت در دسترس انتخاب و طى تماس با روانشناسان و روانيزشكان 


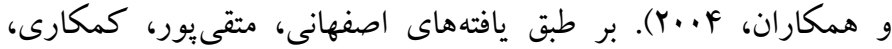

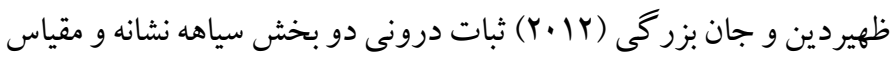

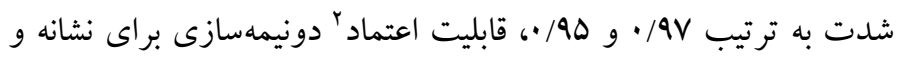

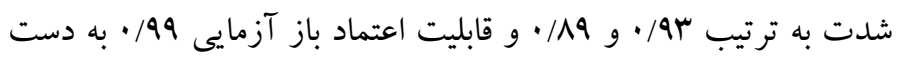

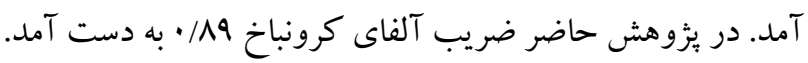

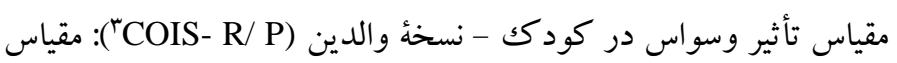

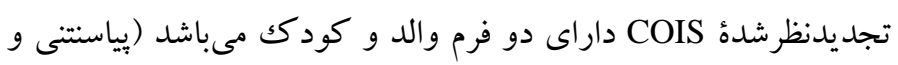

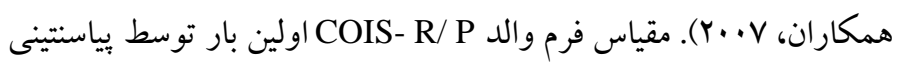
و جفر (1999) تأليف شد و فرم اصلاحشده آن (يياسنتينى و همكاران،

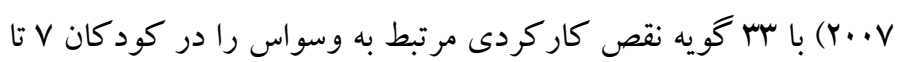
19 ساله مبتلا به اختلال وسواس - ناخوددارى، در جهار بعد عملكرد

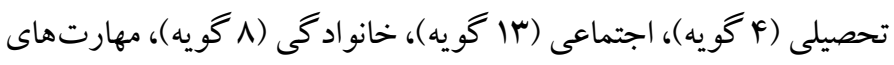

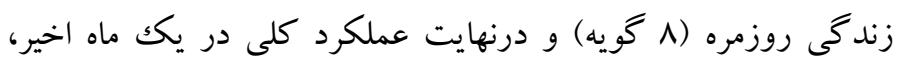

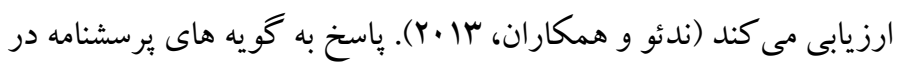

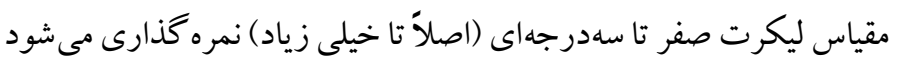
و از والد خواسته مى شود مشخص كند وسواس بر هر مورد خو استهشده در يكك ماه اخير جقدر تأثير كذاشته است. COIS-R/P در بيزوهش بياسنتينى

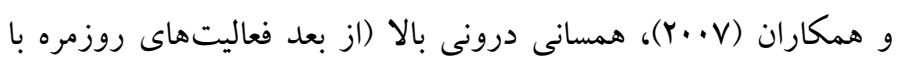

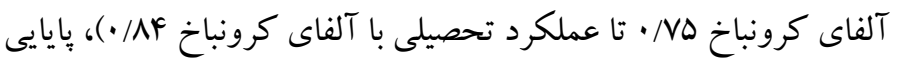

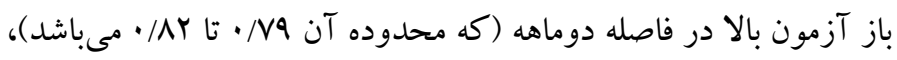

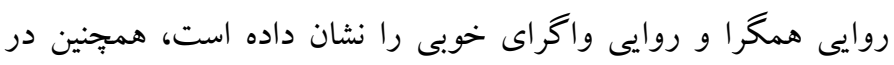

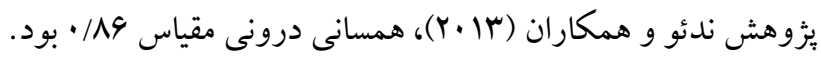

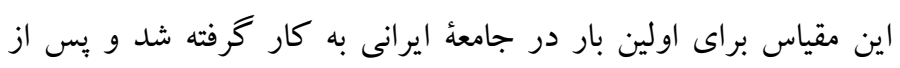

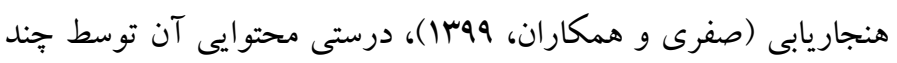

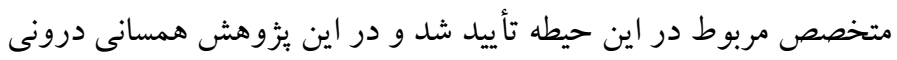
آن از طريق آلفاى كرونباخ هـ/· به دست آمد.

${ }^{3}$. Child Obsessive-Compulsive Impact Scale-Revised(COIS-R)
تدوين و درستى محتوايى آن توسط جند متخصص اين حيطه، بررسى و

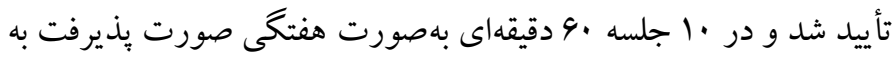

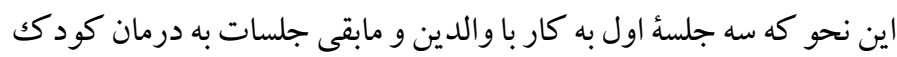

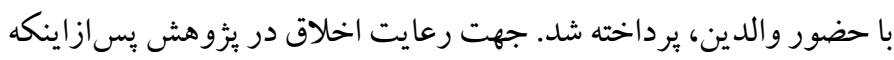
كار آزمايى بالينى توسط كميته اخلاقى با كد

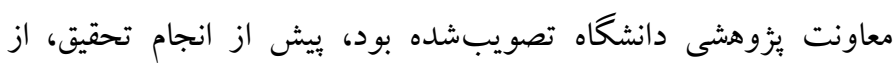
آزمودنىها براى شركت در يثزوهش، رضايتنامه كتبى دريافت شد و

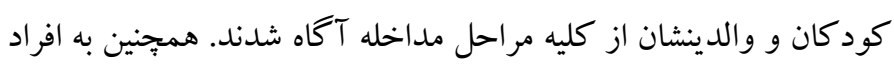
كروه گواه، جهت رعايت اصل اخلاقى عدالت در يُزوهش اطمينان داده

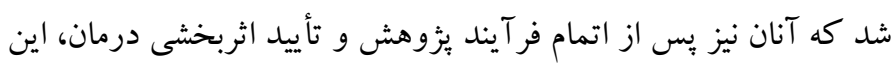

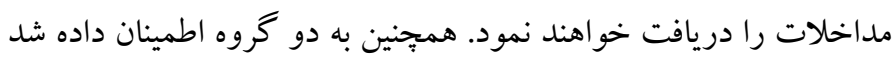

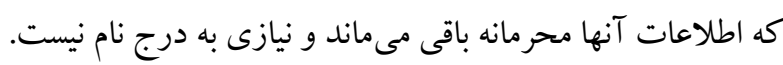

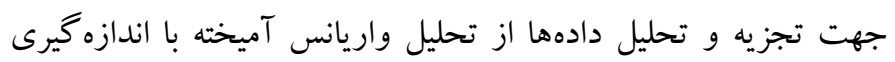
مكرر با استفاده از نرمافزار SPSS استفاده شد. محتواى داى جلسات درمانى به طور مختصر به شرح ذيل بود.

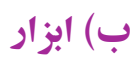
مقياس وسواسى - ناخوددارى ييل براون كود كان ( I I (CY-BOCS): مقياس وسواسى - ناخوددارى ييل براون كود كان (اسكاهيل و همكارانش، 199V) جهت ارزيابى وسواس در كودكان با اقتباس از نسخه بزركسالان، طراحىشده است. CY-BOCS شامل يك جّك ليست علائم و مقياس

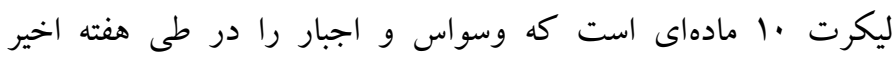

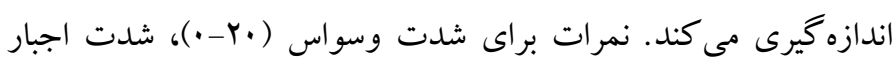

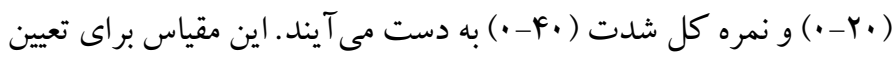

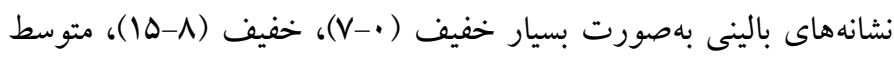

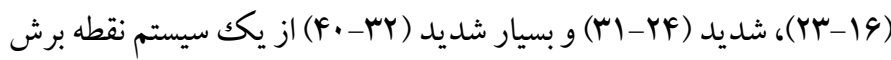
أl با حساسيت •9/· براى تشخيص وسواس در كودكان استفاده مى كند

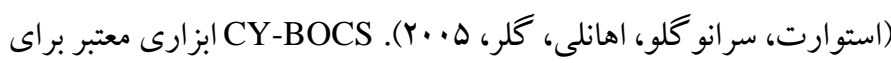
ارزيابى علائم وسواس در كود كان محسوب مى شود. ساز كارى درونى بالا

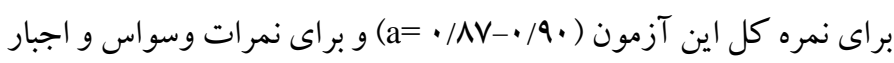

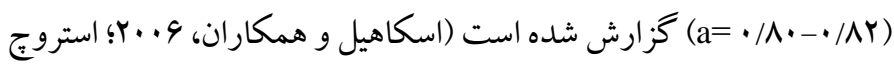

1. Children's Yale-Brown Obsessive Compulsive Scale 2. Reliability 


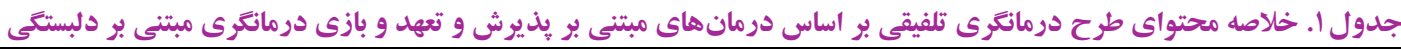
محتوا اهداف رفتارى جلسه جلسات تكاليف

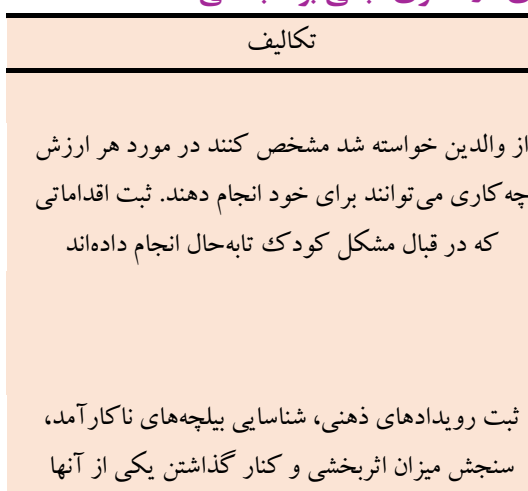

از كودكى خواسته شد رفتارهايى كه خودش و والدينش

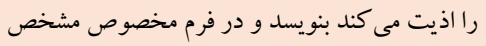

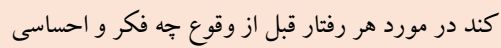
داشته است

كو دك مشخص كند مشكلاتى كه در دنياى بيرون و

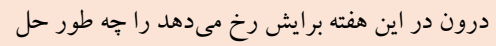

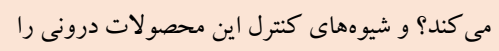
شناسايى كند.

از كودك خو استه شد با شناسايى ببرها، نعره آنها و

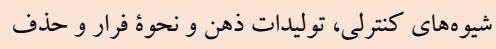

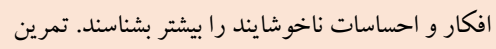

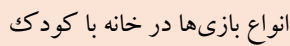

يادداشت كردن رفتارهايى كه بر اساس ارزشهاى

معرفىشده زندكى كودك را بهتر مى كند.

از كود كك خواسته شد با نام گذارى مسافرانى كه براى او

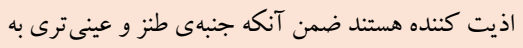

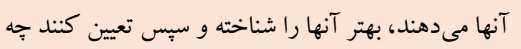

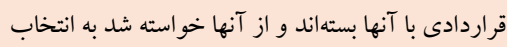
خود لغو يكى از قراردادها را تجربه كنند.

تعميم ץ بعد رفتار مهربانانه به منزل و كمكك به كودكى در لغو قراردادها

كوش دادن به ذهن بدون عمل به آن و در عوض انجام

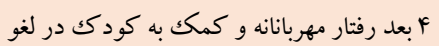
قراردادهاى محكمتر

تحكيم يادگيرىهاى جلسه گذشته
بررسى تعامل والد و كودكى از طريق انجام بازىهاى دونفره، تعريف ماهيت

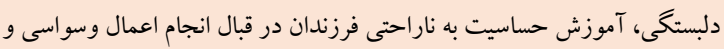

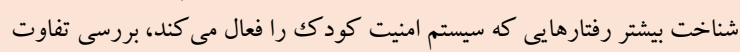

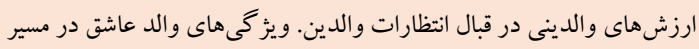

$$
\text { حساسيت هاى والدينى. }
$$

بازخورد به والدين در موردتعامل ضبطشده در جلسه قبل، معرفى ذهن و توليدات

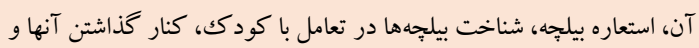

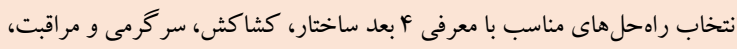

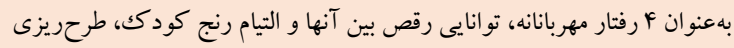
درمان و توضيح روند جلسات

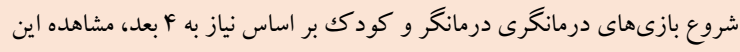

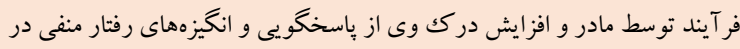

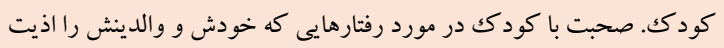

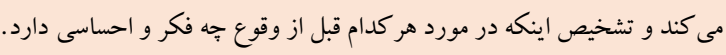

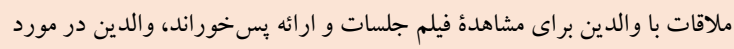

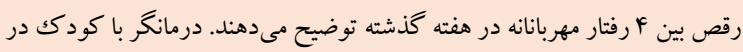

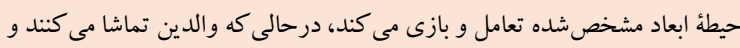

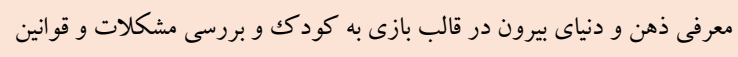
هر كدام

ورود مادر به بازىهاى كودكك و درمانگر كه از قبل بر اساس رابطة تعاملى

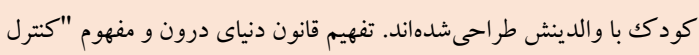
خود مسئله " است با استعاره بير

ملاقات با والدين براى مشاهدة فيلم جلسات و ارائه بِ خور راند ويدئويى و

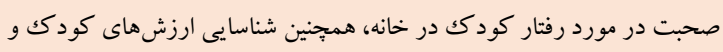

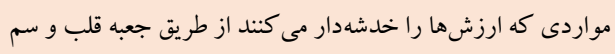

ملاقات با والدين جهت مشاهدة فيلم جلسات و ارائه بس خوخ راند و ارزيابى

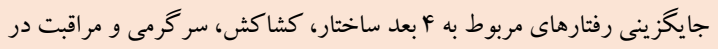

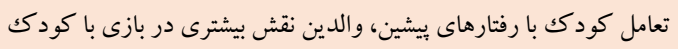

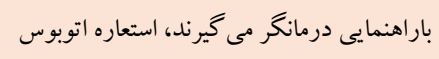

بازخورد درمانكر به والدين در موردتعامل با كودكك در جلسه قبل، بازى كودكك

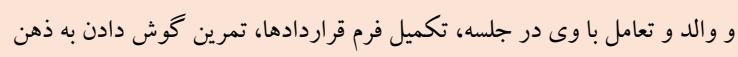

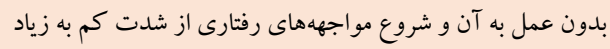

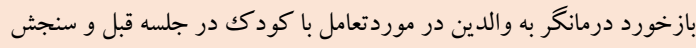

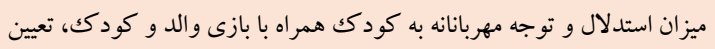

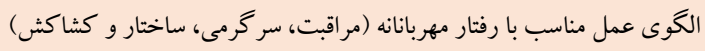

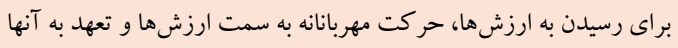

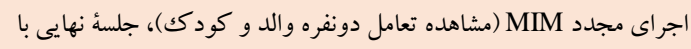

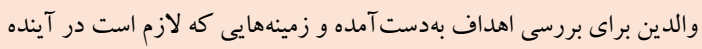

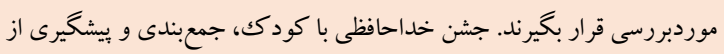

بررسى تعامل والد و كودكى، معرفى رنج فرزند در قبال انجام رفتارهاى وسواسى و تصريح ارزش هاى والدين

ايجاد درماندگى خلاق و شروع

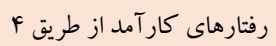
رفتار مهربانانه

مفهومسازى مشكل با كودكك و افزايش دركك والدين از هياسخگويى مبتنى بر دلبستخى

معرفى ذهن و دنياى درون r اجرا و اصلاح رفتارهاى

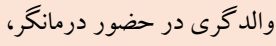
ايجاد درماندگى خلاق در در درو درانكر، كودكى

عينى كردن ارزشهاى مهم كودكى ارزت

معرفى و تمرين بذيرش در كودكى، اجرا و اصلاح رفتارهاى مهربانانه والدگرى در اصراح

حضور درمانگر

تمرين گسلش و طبقهبندى مو اجهه هاى رفتارى تثبيت رفتارهاى والدگرى در

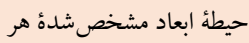
كودك، تعهد به ارزشهاى

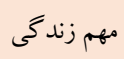

ارزيابى تثبيت \& بعد رويكرد دلبستخى محور در والدين و روني

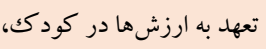
1. 
9/9 بود. نتايج آزمون t بيانگر عدم تفاوت دو گروه در متغير سن

مافْته

بود. (Sig= +N9Y6t $=-\cdot / 1 \wedge 9)$

در جدول Yا، ميانكين و انحراف استاندارد نمرات يِش آزمون، يس آزمون و بيكيرى عملكرد و نشانههاى كودكان مبتلا به وسواس ناخوددارى
از بين ·r كودكك شركت كننده در بثزوهش، 1 كودك يسر (آزمايش: ب نفر، كنترل: ه نفر) و r ا كودكك دختر (آزمايش: V نفر، كنترل: ه نفر)

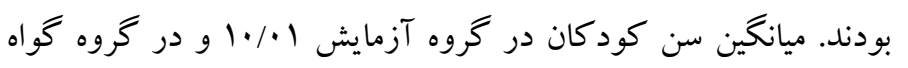

$$
\text { ارائهده است. }
$$

\begin{tabular}{|c|c|c|c|c|c|c|c|}
\hline \multicolumn{2}{|c|}{ ي بيگيرى } & \multicolumn{2}{|c|}{ ي يس آزمون } & \multicolumn{2}{|c|}{ ي بيش آزمون } & \multirow{2}{*}{ خروه } & \\
\hline انحر اف معيار & ميانگين & انحر اف معيار & ميانگين & انحر اف معيار & ميانگين & & \\
\hline $9 / 9$. & $1 F / 9$. & $9 / 09$ & IV & $11 / 9 V$ & rq & آزمايش & \multirow{2}{*}{ عملكرد مر تبط با وسواس كود كان } \\
\hline $9 / \Gamma 1$ & $r V / f$. & १/৭९ & rq/A. & $9 / 91$ & rq & كواه & \\
\hline$r / \cdot 1$ & $r / \Delta$. & $1 / \Delta$ & $r / \Delta$. & $r / T r$ & $V / q$. & آزمايش & \multirow{2}{*}{ عملكرد تحصيلى } \\
\hline$r / 9 V$ & $V / \Delta$ & $r / r q$ & $\mathrm{~V} / \mathrm{A} \cdot$ & $r / r$. & $\mathrm{V} / \mathrm{A}$. & كواه & \\
\hline r & $r / r$. & $r / M$ & $4 / 1$. & $F / Y \Lambda$ & $\Lambda / 1$. & 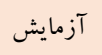 & \multirow{2}{*}{ عملكرد خانوادگى } \\
\hline$f / q$. & $9 / 1$. & $4 / 91$ & $\Lambda / \Lambda$. & $F / \Delta F$ & $\Lambda / r$. & كواه & \\
\hline$F / r \Lambda$ & $9 / r$. & $f / \cdot f$ & $V / r$. & GINF & $10 / r$. & 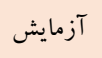 & \multirow{2}{*}{ عملكرد اجتماعى } \\
\hline G/VD & $10 / 9$ & $9 / V^{F}$ & $10 / r$. & $G / Y r$ & $10 / 1$ & كواه & \\
\hline$\cdot / \Delta r$ & $1 / 9$. & $1 / / 49$ & $r / r$. & r/A & $f / v$. & آزمايش & \multirow{2}{*}{ مهارتهاى زندگى روزمره } \\
\hline$r / T F$ & $\Delta / r$. & $r / r \Delta$ & $\Delta$ & $r / F F$ & $f / \Lambda$. & كواه & \\
\hline$r / \Delta q$ & if & $\Gamma / \Lambda \Delta$ & 19 & $F / A F$ & $\mathrm{rV} / \mathrm{I}$. & آزمايش & \multirow{2}{*}{ وسواس كل } \\
\hline$r / v F$ & rV/V. & r/AF & YN/I. & $r / V F$ & $r \wedge$ & كواه & \\
\hline
\end{tabular}

بررسى فرضيه همخنى شيب رگر سيون از آزمون واريانس استفاده شد. نتايج

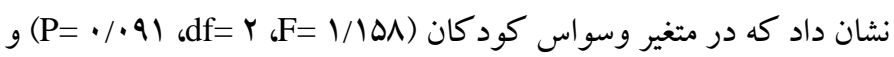

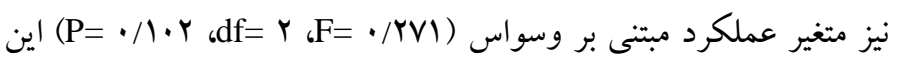
فرضيه برقرار است. همجينين نتايج آزمون لوين نشان مىدهد بيشفرض لوين مبنى بر برابرى واريانس ها در كروهها در متغير وسواس كود كان در

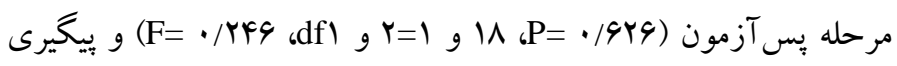

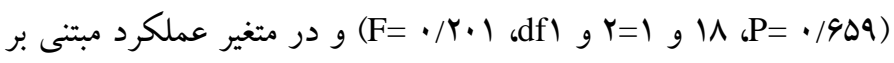

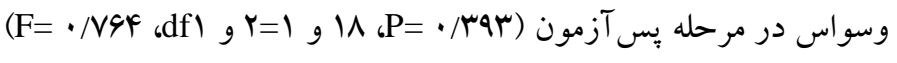

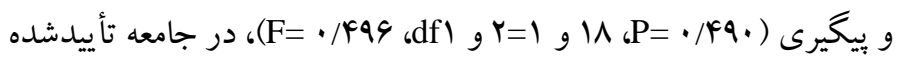

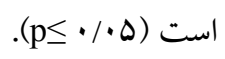

بررسى نتايج آزمون كوويت ماجِلى نشان ميدهد كه در وسواس كود كان

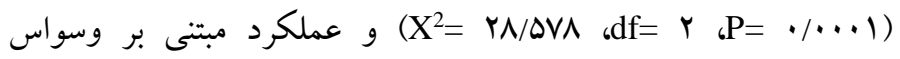
( $)$ مقدار خى خدو بهدست آمده معنادار

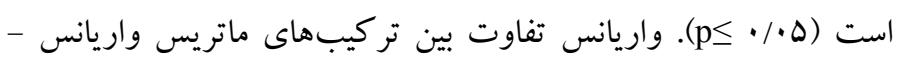
كوواريانس مربوط به اين متغير در كروههاى مورد بررسى يكسان نيست؛
همانطور كه مشاهده مى گردد، نمرات بيش آزمون عملكرد و نشانههاى كود كان مبتلا به وسواس - ناخوددارى در يس آزمون و ييخيرى گروه آزمايش نسبت به كروه كواه تغيير كرده است. بهمنظور بررسى معنادارى اين تفاوت و با توجه به اينكه سه بار هر آزمودنى در معرض اين آزمون

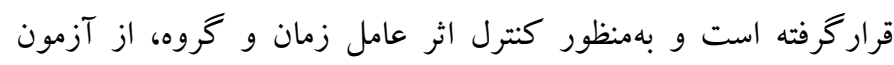
واريانس آميخته با اندازه گيرى مكر استفاده شد. بهمنظور بررسى نرمال بودن دادهها از آزمون شاييرو ويلكز استفاده شد. نتايج اين آزمون نشان

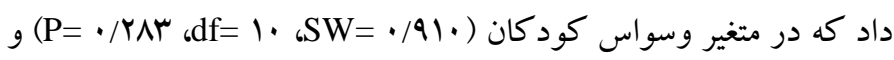

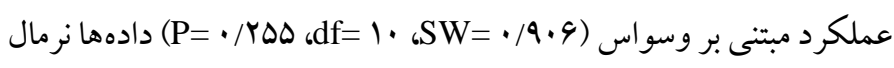
هستند. نتايج آزمون باكس مربوط به شرط همخنى ماتريسهاى واريانس

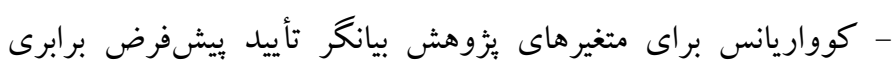
كوواريانسها در همه متغيرها است، درنتيجه يِيشفرض همخن بودن

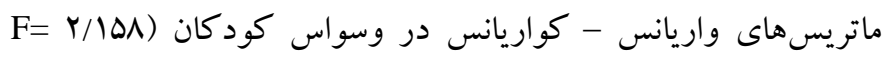
) و عملكرد مبتنى بر وسواس

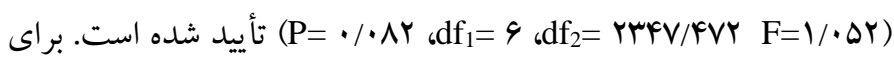


بنابراين از آزمون تصحيح هاوس كيرز استفاده شده است. آزمون هاوس كود كانى كه درمان تركيبى بذيرش و تعهد و بازى درمانگرى دلبستخى

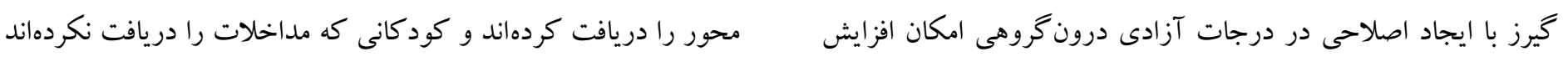

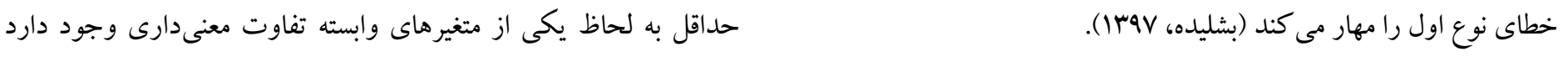

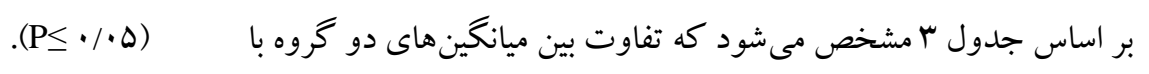

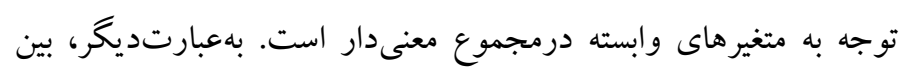

جدول ". نتايج كلى تحليل كوواريانس جند متغيرى تأثير درمان تر كيبى بر عملكرد و علائم كودكان مبتلا به وسواس - ناخوددارى

\begin{tabular}{|c|c|c|c|c|c|c|c|c|c|}
\hline توان آمارى & ضريب اتا & معنى دارى & درجه آزادى خطا & درجه آزادى فرضيه & F & ارزش ارش & منبع تغييرات & متغير & \multirow{2}{*}{ آزمون } \\
\hline $1 / \cdots$ & QF/qRT &.$/ \cdots 1$ & iv & $r$ & $F V / F G V$ & . / $\Delta \Delta r$ & زمان & \multirow{2}{*}{ عملكرد مبتنى بر وسواس } & \\
\hline $1 / \cdot \cdot$ & $\cdot / M$ & $\cdot / \cdots \cdot 1$ & IV & r & $G Y / \cdot V D$ &.$/ 1 r$. & زمانش كروه & & \\
\hline $1 / \cdot$ & $\cdot / A Y V$ & $\cdot / \cdots 1$ & iv & r & $F \cdot / V I V$ &.$/ 14$ & زمان & \multirow{2}{*}{ عملكرد تحصيلى } & \\
\hline $1 / \cdot \cdot$ & - /AFY & $\cdot / \cdots \cdot 1$ & IV & r & $F \Delta / r G q$ &.$/ 10 \Lambda$ & زمان* كروه & & \\
\hline$\cdot / 9 V F$ & $\cdot / \Delta 9$ & $\cdot / \cdot 1$ & iv & r & $1 \cdot / \Lambda \cdot \Delta$ & - / $F F$. & زمان & \multirow{2}{*}{ عملكرد خانوادگى } & \\
\hline $1 / \cdot$ & $\cdot / \mathrm{NIA}$ & $\cdot / \cdots \cdot 1$ & iv & r & rI/gTI & . TAN & زمان* گروه & & لامبداى \\
\hline $1 / \cdot \cdot$ & - /AYA & $\cdot / \cdots \cdot 1$ & iv & r & $r \cdot / 9 \wedge r$ & $\cdot / \mathrm{Vr}$ & زمان & \multirow{2}{*}{ عملكرد اجتماعى } & ويلكز \\
\hline $1 / \cdot \cdot$ & - MAr & $\cdot / \cdots \cdot 1$ & iv & r & $q 4 / . r q$ &.$/ 11 V$ & زمان*گگروه & & \\
\hline ./^9. & - / $4 a 4$ & $\cdot / \cdot \Delta$ & IV & r & $V / r 40$ & . /Drq & زمان & \multirow{2}{*}{ مهارتهاى روزمره } & \\
\hline.$/ 99$. & $\cdot 19 \cdot r$ & $\cdot / \cdots+1$ & iv & r & $|r / 9| \wedge$ & $\cdot /$ rqv & زمانش گروه & & \\
\hline $1 / \cdot \cdot$ & - /NOT & $\cdot / \cdots \cdot 1$ & IV & r & rq//Ar & $\cdot / I F V$ & زمان & \multirow{2}{*}{ وسواس كل } & \\
\hline $1 / \cdot \cdot$ & $\cdot / 1 / \Delta$ & $\cdot / \cdots \cdot 1$ & iv & r & TV/DFF & . /NA & زمان* گروه & & \\
\hline
\end{tabular}

جدولع. واريانس آميخته با اندازه كيرى مكرر (تأثير درمان تر كيبى بر عملكرد و علائم كود كان مبتلا به وسواس - ناخوددارى)

\begin{tabular}{|c|c|c|c|c|c|c|c|c|c|}
\hline \multirow{2}{*}{ 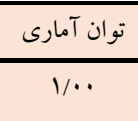 } & \multirow{2}{*}{ مجذور اتا } & \multirow{2}{*}{ معنادارى } & \multirow{2}{*}{$\frac{F}{9 q / \cdot 9 r}$} & \multirow{2}{*}{ ميانگين مجذورات } & \multirow{2}{*}{ درجه آزادى } & \multirow{2}{*}{ مجموع مجذورات } & \multicolumn{2}{|c|}{ منبع تغييرات } & \multirow[t]{2}{*}{ متغير } \\
\hline & & & & & & & زمان & & \\
\hline $1 / \cdot$ & $\cdot / 1999$ & $\cdot / \cdots 1$ & $11 N / \wedge \Delta$ & $|r r q| \cdot v \wedge$ & l/rr. & $10 \cdot 9 / \mu \ldots$ & گروهمزمان & & عملكرد مبتنح \\
\hline.$/ 91$. & $\cdot / f \cdot f$ & . . r & $\mid r / r \cdot r$ & rQAY/lQ. & 1 & rQAST/lQ. & گروه & بين گروهى & وسواس \\
\hline $1 / \cdot \cdot$ & $.19 \mathrm{Vr}$ & $\cdot / \cdots 1$ & $\mathrm{rV} / \cdot 19$ & $\Delta r / \Delta \cdot \Delta$ & l/Yaf & 99/rTr & زمان & & \\
\hline $1 / \cdot \cdot$ &.$/ 94 Y$ & $\cdot / \cdots+1$ & IIIIII & $k q / V \cdot F$ & I/TaF & 9./4m & گروهـزمان & & عملكرد تحصيلى \\
\hline$\cdot|\wedge|$. & $\cdot / M r F$ & $\cdot / \cdot \wedge$ & $9 / \cdots \wedge$ & $11 \mathrm{r} / .9 \mathrm{~V}$ & 1 & $11 \mathrm{r} / .9 \mathrm{~V}$ & كروه & بين گروهى & \\
\hline.$/ 999$ & . /0r4 & $\cdot / \cdots+1$ & $r \cdot / v \wedge G$ & rq/qvq & $1 / 1 M$ & $F V / \Delta$. & زمان & & \\
\hline $1 / \cdot \cdot$ &.$/ 9 A r$ & $\cdot / \cdots 1$ & HA/OYF & $V F / \cdot 1 q$ & $1 / M M$ & N/. & گروهمزمان & & عملكرد خانو ادگى \\
\hline . & $\cdot / r \cdot r$ &.$/ F V$ & $F / \Delta F V$ & $19 \cdot / \mathrm{AlV}$ & 1 & $19 \cdot / 11 \mathrm{~V}$ & كروه & & \\
\hline $1 / \cdot$ & $\cdot / A \cdot r$ & $\cdot / \cdots 1$ & $V r / 4.1$ & rIT/MDA & $1 / \cdot \wedge \cdot$ & 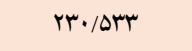 & زمان & & \\
\hline $1 / \cdot$ & - IAYG & $\cdot / \cdots+1$ & $\Lambda \Delta / G Y V$ & YAF/AQA & $1 / \cdot \wedge$. & rGN/ATr & گروهـزمان & & عملكرد اجتماعى \\
\hline.$/ \Delta F \Delta$ &.$/ Y 11$ & $\cdot / \cdots 1$ &.$/ F r$ & $\mathrm{FqT/.9V}$ & 1 & $\mathrm{FqF} / .9 \mathrm{~V}$ & گروه & بين گروهى & \\
\hline.$/ 9 V r$ & - / Frr & $\cdot / \cdots+1$ & IT/ITr & $1 r / 9 V Y$ & $1 /$ HFA & NN/FrT & زمان & & \\
\hline.$/ 991$ & $\cdot / \Delta F$. & $\cdot / \cdots 1$ & $r \mid / 111$ & $r \mid / 9 V q$ & $1 / F F A$ & $r Q / 9 \pi r$ & گروهوزمان & & \\
\hline$\cdot / D F A$ & $\cdot / r I r$ &.$/ .41$ & f/Ard & $94 / .9 \mathrm{~V}$ & 1 & $94 / .9 \mathrm{~V}$ & كروه & بين گروهى & رورمره \\
\hline $1 / \cdot$ & - /Ara & $\cdot / \cdots 1$ & $9 F / .9 Y$ & $1.94 / 9 \cdot 1$ & l/T. & Ir. r/gmT & زمان & دورن & \\
\hline $1 / \cdot$ & $\cdot / 191$ & $\cdot / \cdots \cdot 1$ & $11 N \cdot \wedge \Delta$ & $|m+9| \cdot v \wedge$ & l/T. & $10 \cdot 9 / r \ldots$ & گروهـزمان & & وسواس كل \\
\hline.$/ 91$. & $\cdot / f \cdot F$ & 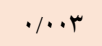 & $\mid r / r \cdot r$ & $r Q \wedge r / l \Delta$. & 1 & $r Q \wedge r / l \Delta$. & كروه & بين گروهى & \\
\hline
\end{tabular}


توانشهاى زندكى روزمره (P)

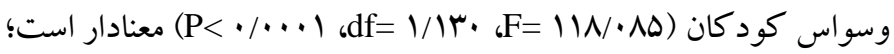
بنابر اين مى توان كفت، تفاوت ميانخين نمرات عملكرد و نشانه هاى كود كان در زمانهاى مختلف با تو جه به سطوح متغير گروه متفاوت است. همانطور كه در جدول مشاهده مىشود، تأثير گروه نيز بر نمرات عملكرد مبتنى بر وسواس (T/Y/Y

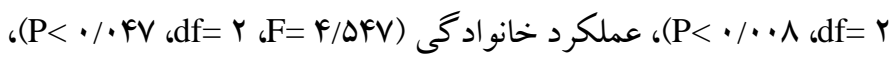

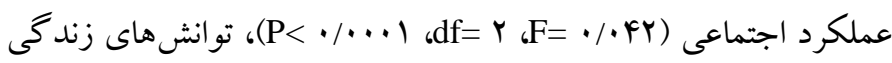
روزمره (Dش/A كه صرفنظر از زمان اندازهگيرى، بين ميانگين نمرات عملكرد مرتبط با وسواس و نيز وسواس كود كان تفاوت معنادار وجود دارد.
نتايج جدول \& گ \&ياى آن است كه تأثير زمان اندازهيرى بر نمرات

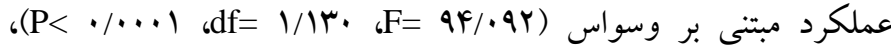

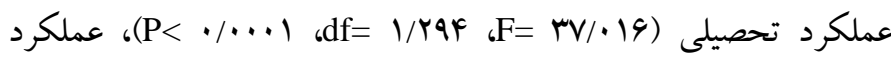

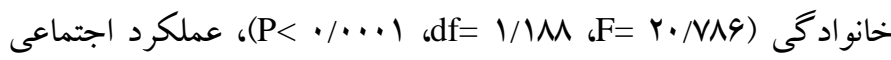

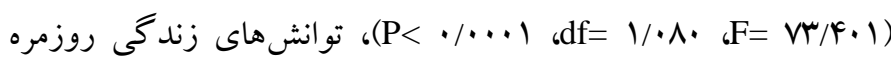

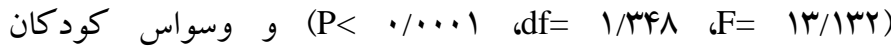
(P< معنادار است؛ بنابر اين مى توان بيان كرد كه صرفنظر از كروه آزمايش، بين نمرات در بيش آزمون، بِ آزمون و بيخيرى، تفاوت معنادارى وجود دارد. همجِين اثر تعامل زمان

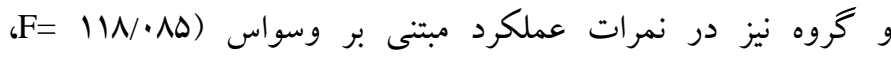

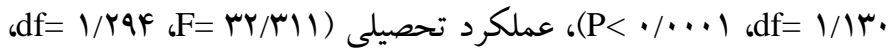

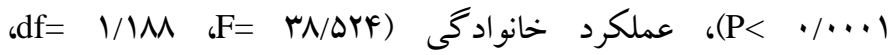

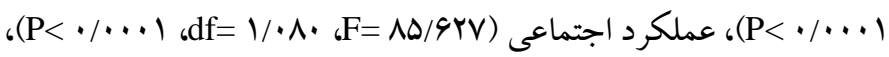

\begin{tabular}{|c|c|c|c|c|}
\hline سطح معنادارى & تفاوت ميانگين (i-j) & مرحله (j) & مرحله (i) & 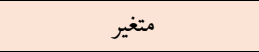 \\
\hline$\cdot / \cdots 1$ & $9 / 1 \ldots$ & يس آزمون & & \\
\hline$\cdot / \cdots 1$ & Q/^১. & بيخيرى & س 'رمون & عملكرد مبتنى بر وسو اس \\
\hline.$/ . \Delta$ & ./va. & ييخيرى & يس آزمون & \\
\hline$\cdot / \cdots \cdot 1$ & $r / Y_{\cdots}$ & يس آزمون & 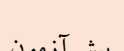 & \\
\hline$\cdot / \cdots 1$ & $r / T \Delta$. & ييخيرى & بِي & عملكرد تحصيلى \\
\hline 1 &.$/ 10$ & بيخيرى & يس آزمون & \\
\hline.$\cdots 1$ & $1 / V \Delta$. & يس آزمون & & \\
\hline$\cdot \cdots 1$ & r & ييخيرى & يست ارمون & عملكرد خانو ادگى \\
\hline . MIF & $\cdot / r \Delta$ & ييخيرى & ي بس آزمون & \\
\hline$\cdot / \cdots \cdot 1$ & r & يس آزمون & & \\
\hline$\cdot / \cdots 1$ & $r / r \ldots$ & ييخيرى & & عملكرد اجتماعى \\
\hline.$/ . \mathrm{kr}$ & $\cdot / \mu \cdot$ & ي يجيرى & يس آزمون & \\
\hline$\cdot / \cdot \Delta$ & $1 / 10$ & يس آزمون & & \\
\hline$\% r$ & $1 / r$. & 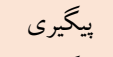 & إزمون & مهارتهاى زندگى روزمره \\
\hline 1 &.$/ \Delta$ & ي ييخيرى & يس آزمون & \\
\hline$\cdot \cdots 1$ & $\Delta / \Delta \cdot \cdot$ & يس آزمون & سش آزمون & \\
\hline$\cdot / \cdots 1$ & $9 / \mathrm{V} \cdot$ & ي ييخيرى & & وسواس كل \\
\hline$\cdot / \cdot 1$ & $1 / \% \cdots$ & ييخيرى & يس آزمون & \\
\hline
\end{tabular}

كاهش علائم و بهبود عملكرد كودكان مبتلا به اختلال وسواس ناخوددارى مؤثر است. اين يافته درزمينهُ درمان مبتنى بر بذيرش و تعهد،

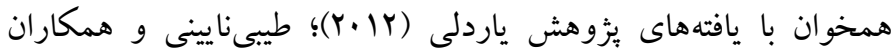

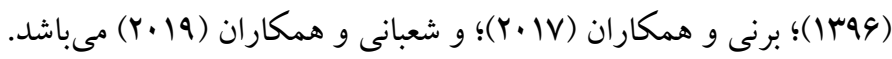

بحث و نتيجه تيرى هدف از اين يُزوهش، اثربخشى درمان تركيبى بذيرش و تعهد و بازى درمانگرى دلبستخى محور بر علائم و عملكرد كود كان مبتلا به اختلال وسواس - ناخوددارى بود. يافتها نشان داد كه درمان به كاررفته شده بر 
اجتماعى (كيم، رينولدز و آلفانيو، Y (Y.T)، كودكان مبتلا به وسواس

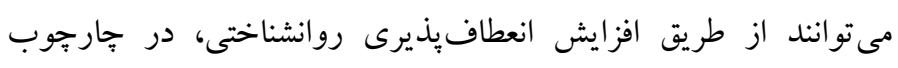

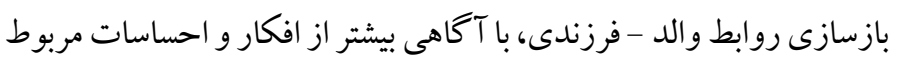

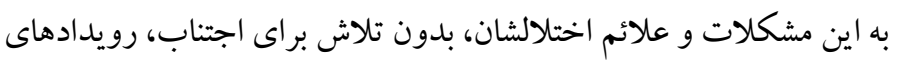

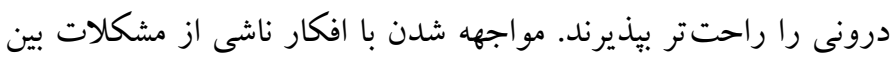

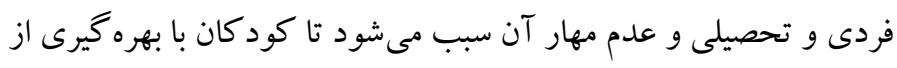

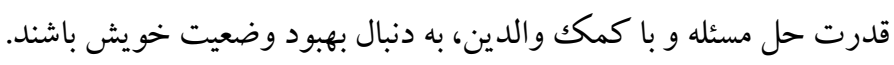

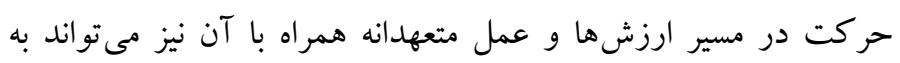

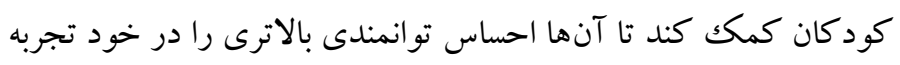
كنند كه درنتيجه حس خود كار آمدى آنها ارتقا مى يابد. در اين شيوه

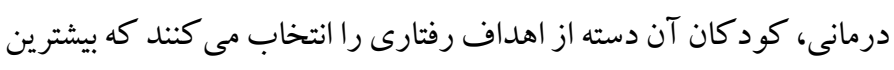

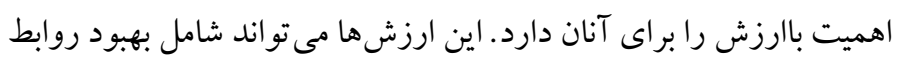

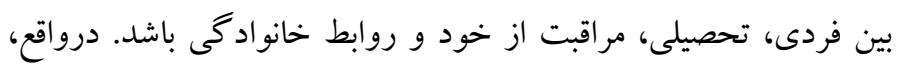

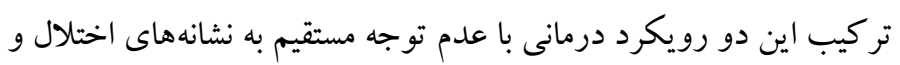

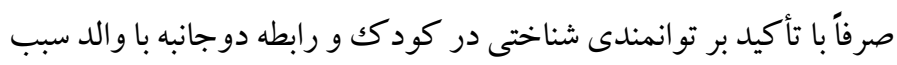

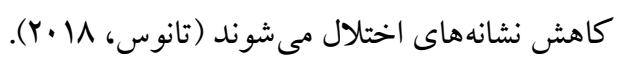

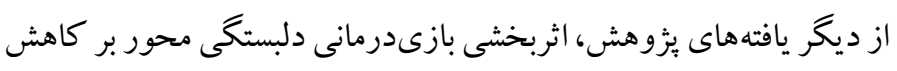
علائم اختلال وسواس - ناخوددارى و افزايش عملكرد كود كان مبتلا بود. تحقيقات ييشين بررسى زيادى در مورد اثربخشى اين درمان بر اختلال وسواس - ناخوددارى كود كان نداشتهاند؛ اما از آنجايى كه علائم اختلال

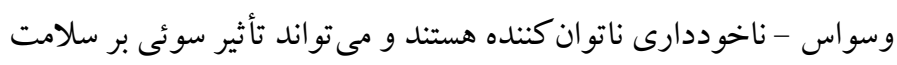
فردى و روابط والد - فرزندى داشته باشد، تلاش براى كاهش علائم تجربه

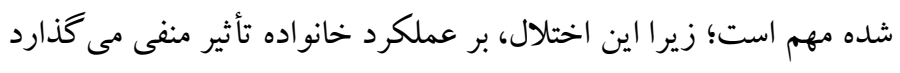

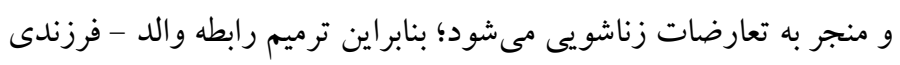

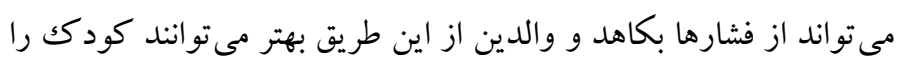
در جهت رهايى از وسواس يارى دهند. بازىدرمانى به كود كان يكك روش

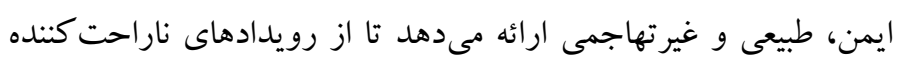

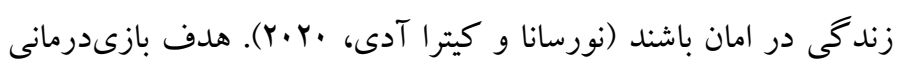

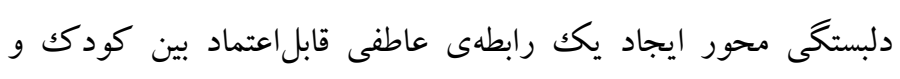

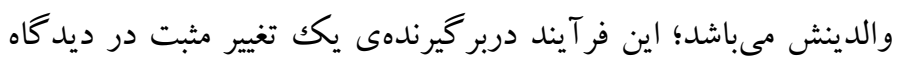
تأثير گذار درونى كودكك نسبت به خود و انتظارى است كه از تعامل با بال والدينش دارد. همجنين ديد كاه درونى والدين نسبت به خودشان و ذهنيت
فقدان انعطاف بذيرى روانشناختى با نشانگان اختلال وسواس در كود كان و

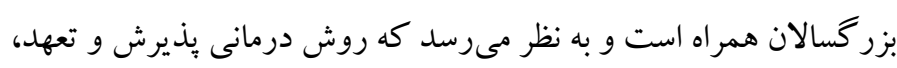

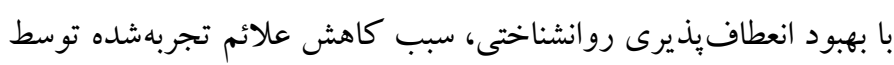

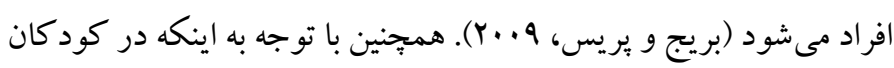

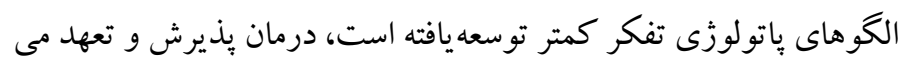

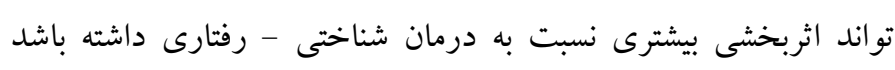

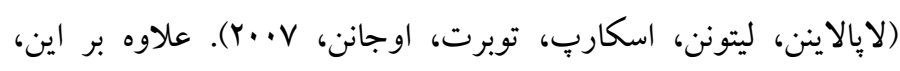

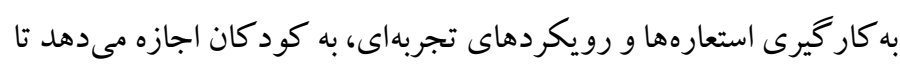
مفاهيم انتزاعى را از طريق تجربه درك كنيد (اوبرين، لارسون و مورل،

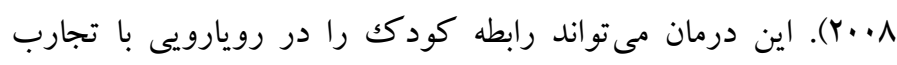

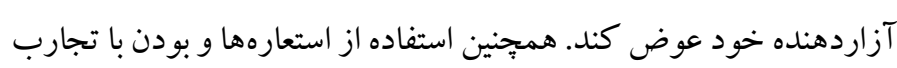

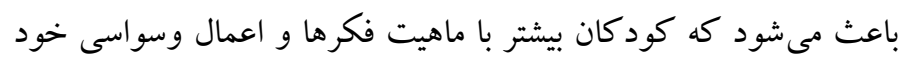

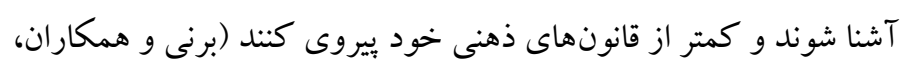

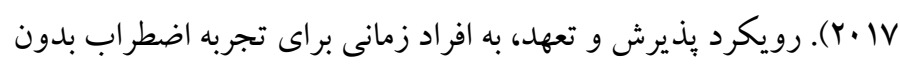

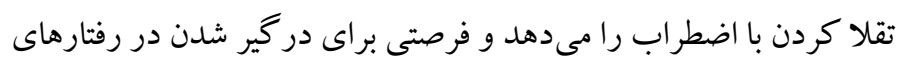

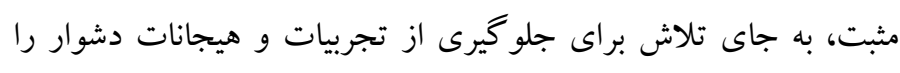

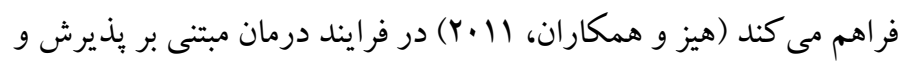

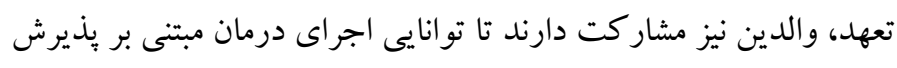

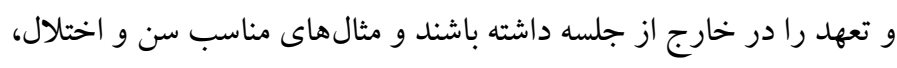

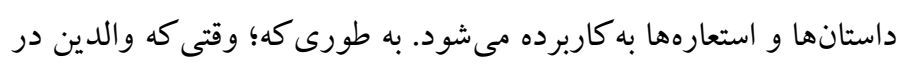

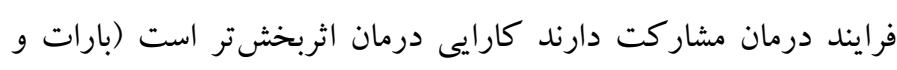

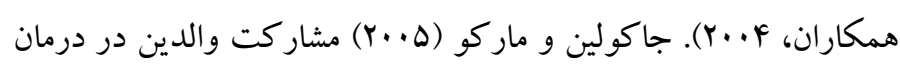

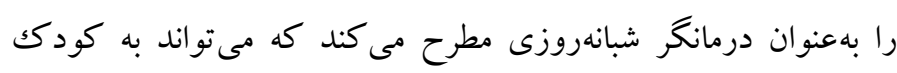

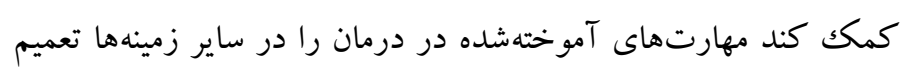
دهد. اثربخشى درمان بذيرش و تعهد و بازى درمانخرى مبتنى بر دلبستحى، بر

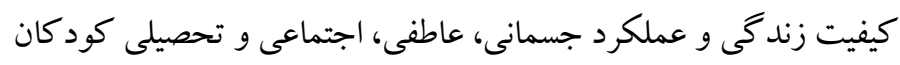

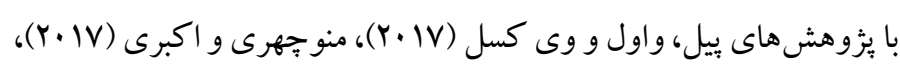

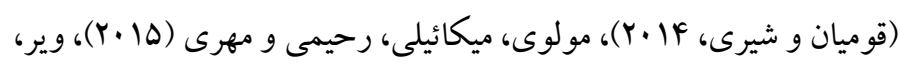

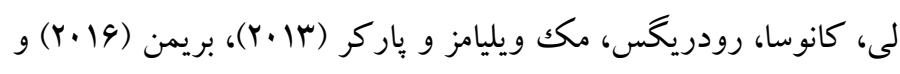

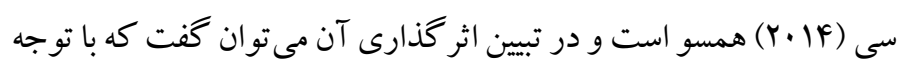

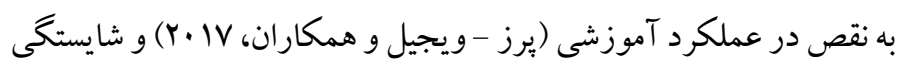


ارتباط بين والد و كودك تأثير مستقيم دارد و با كاهش علائم اختلال در

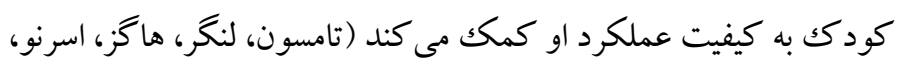

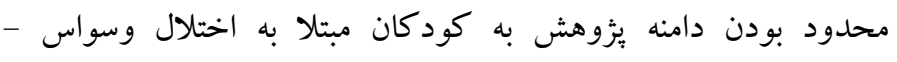
ناخوددارى شهر اصفهان و وجود برخى متغيرهاى كنترل نشده مانند

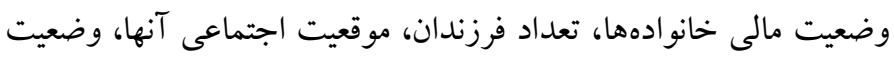

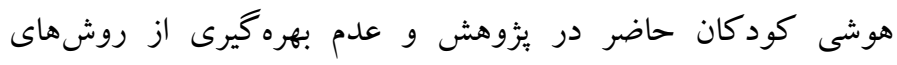
نمونه گيرى تصادفى از محدوديتهاى اين بزوهش بود؛؛ لذا با توجه به نتايج

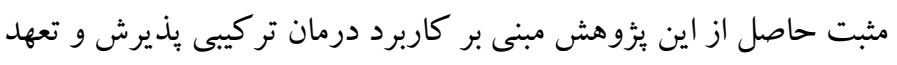

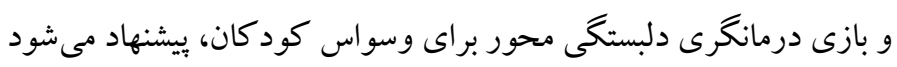

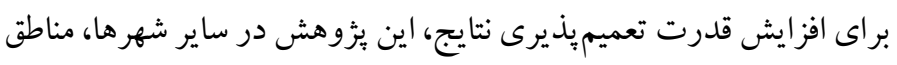

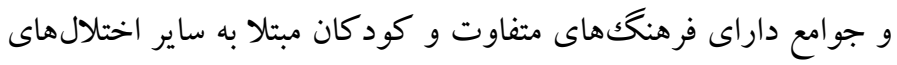
روانشناختى، با كنترل عوامل ذكرشده و روش نمونه گيرى تصادفى اجرا شود. همجنين در سطح كاربردى بيشنهاد مى شود اين درمان در مراكز

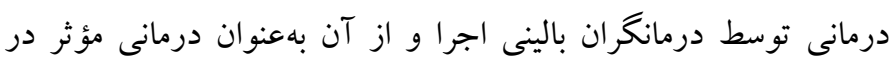

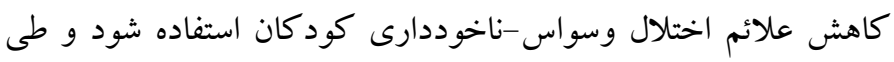
كار كاهى تخصصى به مشاوران مدارس آموزش داده شود تا تا آنها با با

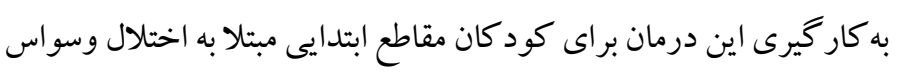

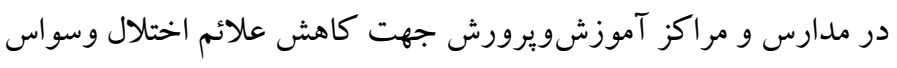
- ناخوددارى اين دانش آموزان گامى عملى برداشته باشند.

\section{ملاحضات اخلاقى}

بيروى از اصول اخلاق ئوهش: اين مقاله بركرفته از رساله دكترى نويسنده اول

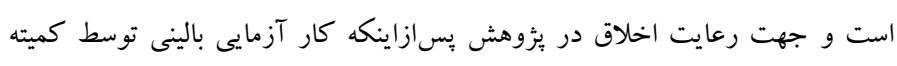

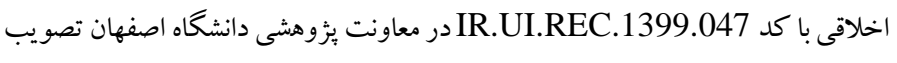

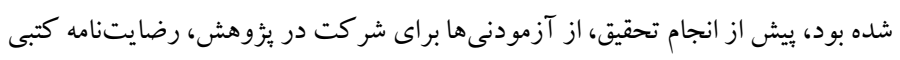

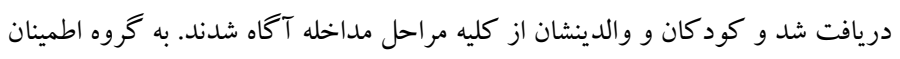

داده شد كه اطلاعات آنها محرمانه باقى مى ماند و نيازى به درج نام نيست.

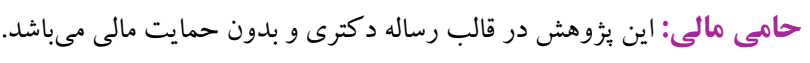

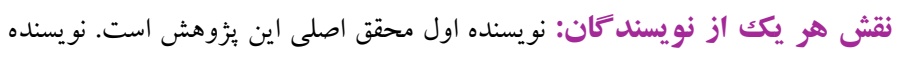

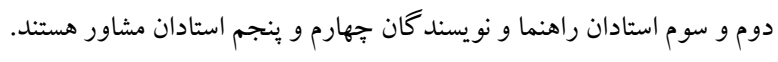

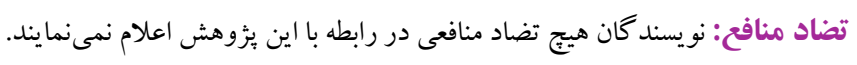

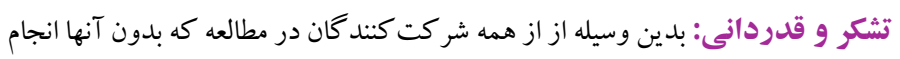
اين تحقيق امكانيذير نبود قدردانى مي كنيم.
آنها نسبت به فرزندشان مثبت تر خواهد شد. تجربهى هماهنكى و انطباق با

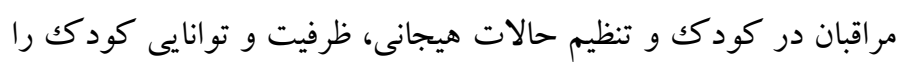
براى خودتنظيمى افزايش خواهد داد. بهعلاوه رفتارهاى مشكل آفرينى كه ونه

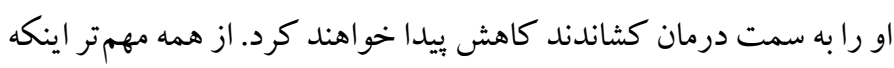
درمان منجر به طيف گستردهاى از نتايج مثبت مرتبط با دلبستكى ايمن از

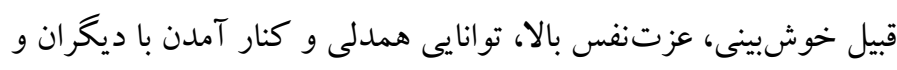

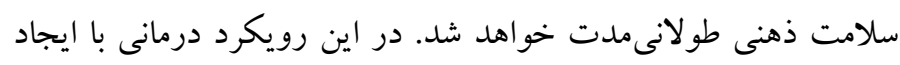

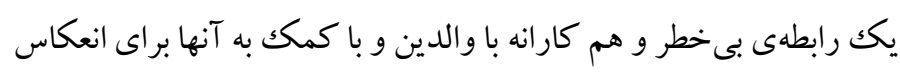

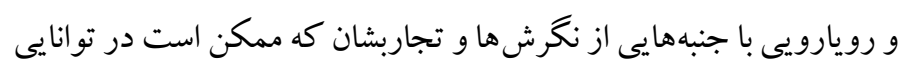

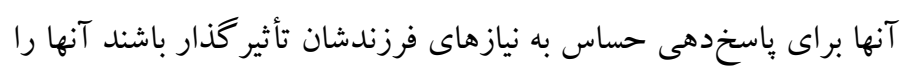

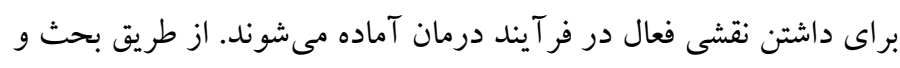

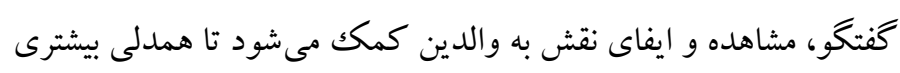

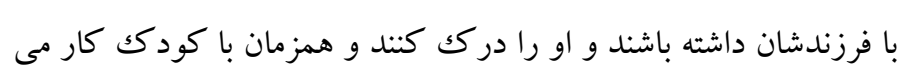

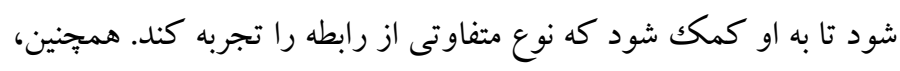
بازىدرمانى دلبستخى محور مى تواند علاوه بر كاهش اضطر اب، هيجانات

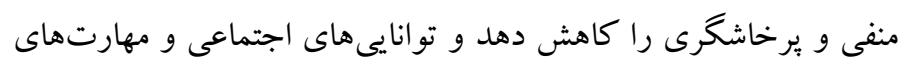

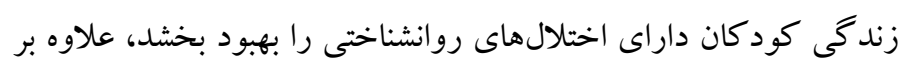
اين در بازى درمانكرى دلبستخى محور انواع مختلفى از بازىها و و وسايل

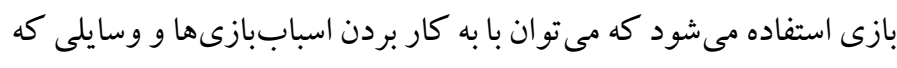

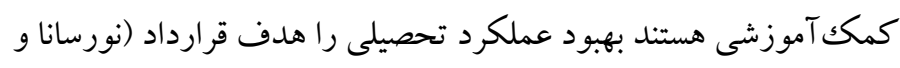

$$
\text { كيترا آدى، ·r.r. (r. }
$$

در طول درمان تركيبى بذيرش و تعهد و بازى درمانگرى دلبستخى محور،

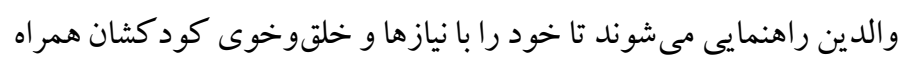

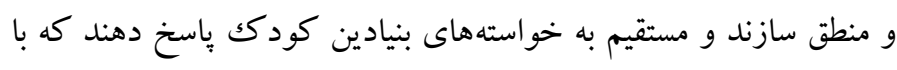

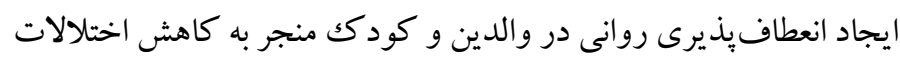

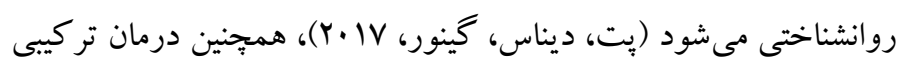

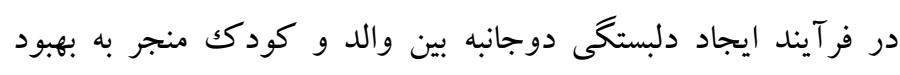

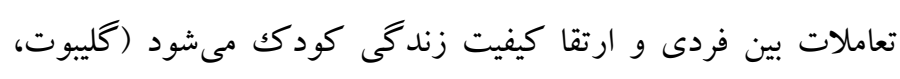

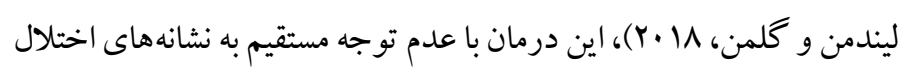
و صرفاً با تأكيد بر توانمندى شناختى در كودكك و رابطه دوجانبه با والد، سبب كاهش نشانهاى اختلال مىشود (وان ليوون و همكاران، .r.r)

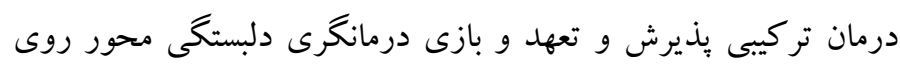




\section{References}

Armstrong, A. B., Morrison, K. L., \& Twohig, M. P. (2013). A preliminary investigation of acceptance and commitment therapy for adolescent obsessivecompulsive disorder. Journal of Cognitive Psychotherapy, 27(2), 175-190. [Link]

Asli Azad M, Manshaei G, Ghamarani A. (2019). The effectiveness of acceptance and commitment therapy on the obsessive-compulsive syndrome and thought-action fusion in students with obsessivecompulsive disorder. Journal of Psychological Science, 18(73). 67-76. (Persian). [Link].

Baribeau, D. E., Doyle-Thomas, K., Dupuis, A., Iaboni, A., Crosbie, J., McGinn, H., Arnold, P. D., Brian, J., Kushki, A., et al. (2015). Examining and Comparing Social Perception Abilities Across Childhood Onset Neuro developmental Disorders. $J$ Am Acad Child AdolescPsychiatry, 54(6), 479-86. [Link]

Barney, J. Y., Field, C. E., Morrison, K. L., \& Twohig, M. P. (2017). Treatment of pediatric obsessive compulsive disorder utilizing parent facilitated acceptance and commitment therapy. Psychology in the Schools, 54(1), 88-100. [Link]

Barrett, P., Healy-Farrell, L., \& March, J. S. (2004). Cognitive-behavioral familytreatment of childhood obsessive-compulsive disorder: A controlled trial. Journalof the American Academy of Child and Adolescent Psychiatry, 43(1), 46-62. [Link]

Brezinka, V., Mailänder, V., \& Walitza, S. (2020). Obsessive compulsive disorder in very young children-a case series from a specialized outpatient clinic. BMC psychiatry, 20(1), 1-8. [Link]

Briggs, E. S., \& Price, I. R. (2009). The relationship between adverse childhood experience and obsessive-compulsive symptoms and beliefs: the role of anxiety, depression, and experiential avoidance. Journal of anxiety disorders, 23(8), 1037-1046. [Link]

Chen, D., Bienvenu, O. J., Krasnow, J., Wang, Y., Grados, M. A., Cullen, B., ... \& Rasmussen, S. A. (2017). Parental bonding and hoarding in obsessivecompulsive disorder. Comprehensive psychiatry, 73, 43-52. [Link]

Dadashzadeh, H., Musazadeh, T., Yusefi, M. E., \& Amiri, S. (2018). Attachment styles of patients with major depressive, obsessive-compulsive, and generalized anxiety disorders. Journal of Research in Clinical Medicine, 6(1), 34-42. [Link]
Doron, G., Moulding, R., Nedeljkovic, M., Kyrios, M., Mikulincer, M., \& Sar-El, D. (2012). Adult attachment insecurities are associated with obsessive compulsive disorder. Psychology and psychotherapy: theory, research and practice, 85(2), 163-178. [Link]

Esfahani, S. R., Motaghipour, Y., Kamkari, K., Zahiredin, A., \& Janbozorgi, M. (2012). Reliability and Validity of the Persian Version of the Yale-Brown Obsessive-Compulsive Scale (Y-BOCS). Iranian Journal of Psychiatry \& Clinical Psychology, 17(4), 297-303. (Persian). [Link]

Fineberg, N. A., Dell'Osso, B., Albert, U., Maina, G., Geller, D., Carmi, L., ... \& Hollander, E. (2019). Early intervention for obsessive compulsive disorder: an expert consensus statement. European Neuropsychopharmacology, 29(4), 549-565. [Link]

Fineberg, N.A., Dell'Osso, B., Albert, U., Maina, G., Geller, D.A., Carmi, L., et al. (2019). Early intervention for obsessive compulsive disorder: an expert consensus statement. European Neuro psycho pharmacology, 29(4), 549-565. [Link]

Francis, Y. J., Bennion, K., \& Humrich, S. (2017). Evaluating the outcomes of a school based Theraplay ${ }^{\circledR}$ project for looked after children. Educational Psychology in Practice, 33(3), 308322. [Link]

Ghomian, S., \& Shairi, M. R. (2014). The effectiveness of acceptance and commitment therapy for children with chronic pain on the quality of life on 7 to 12 year-old children. International Journal of Pediatrics, 2(3.2), 47-55. [Link]

Glibota, L. C., Lindaman, S., \& Coleman, A. R. (2018). Theraplay as a Treatment for Children with Selective Mutism. Play-Based Interventions for Childhood Anxieties, Fears, and Phobias, 124. [Link]

Goli, E., Abdekhodaie, M. S., Mashhadi, A., \& Bigdeli, I. (2020). The role of parent-child interaction patterns in the development of obsessive-compulsive disorder: A literature review study. Journal of Fundamentals of Mental Health, 22(1), 5-20. [Link]

hasani S, mehrinezhad A, khodabakhsh pirkalani R. (2020). Comparison of the effectiveness of exposure, mindfulness and mindfulness - integrated exposure on arak women obsessive - compulsive disorder. Journal of Psychological Science, 86(19), 137-145. [Link].

Hashemi Jashni A, Roushan R, Ahadi, H. (2020). Compare the efficacy of exposure therapy and prevention of response and group acceptance and 
commitment therapy in reducing the severity of symptoms in patients with obsessive-compulsive disorder, Journal of Psychological Science, 19 (93).1141-1148. (Persian). [Link]

Hayes, S. C., Levin, M. Plumb-Vilardaga, J., Villatte, J. L, \&Pistorello, J. (2013). Acceptance and commitment therapy and contextual behavioral science: Examining the progress of a distinctive modelof behavioral and cognitive therapy. Behavior therapy, 44(2), 180-198. [Link]

Jacqueline, M. L., \& Margo, T. (2005). Group cognitivebehavior therapy with family involvement for middle-school-age children with obsessivecompulsive disorder: A pilot study. Child Psychiatry \& Human Development, 36(1), 113-127. [Link]

Jamshidi M, Khayatan F, Aghaie A. (2020). Comparison of the effectiveness of combination of acceptance and commitment therapy with theraplay and acceptance and commitment therapy on quality of life in depressed children, 8 (1). 106-118. (Persian). [Link]

Kim, K. L., Reynolds, K. C., \&Alfano, C. A. (2012). Social impairment in children with obsessive compulsive disorder: Do comorbid problems of inattention and hyperactivity matter?Journal of Obsessive-Compulsive and Related Disorders, 1(4), 228-233. [Link]

Krebs, G., \& Heyman, I. (2015). Obsessive-compulsive disorder in children and adolescents. Archives of disease in childhood, 100(5), 495-499. [Link]

Lappalainen, R., Lehtonen, T., Skarp, E., Taubert, E., Ojanen, M., \& Hayes, S. C. (2007). The impact of CBT and ACT models using psychology trainee therapists: A preliminary controlled effectiveness trial. Behavior modification, 31(4), 488-511. [Link]

Lennertz, L., Grabe, H. J., Ruhrmann, S., Rampacher, F., Vogeley, A., Schulze-Rauschenbach, S., ... \& Pukrop, R. (2010). Perceived parental rearing in subjects with obsessive-compulsive disorder and their siblings. Acta Psychiatrica Scandinavica, 121(4), 280-288. [Link]

Molavi P, Mikaeili N, Rahimi N, Mehri S. (2015). The Effectiveness of Acceptance and Commitment Therapy Based on Reducing Anxiety and Depressionin Students with Social Phobia. J ArdabilUniv Med Sci. 14 (4):412-423. (Persian). [Link]

Myhr, G., Sookman, D., \& Pinard, G. (2004). Attachment security and parental bonding in adults with obsessive-compulsive disorder: A comparison with depressed out-patients and healthy controls. Acta Psychiatrica Scandinavica, 109, 447-456. [Link]

Nadeau, J. M., Lewin, A. B., Arnold, E. B., Crawford, E. A., Murphy, T. K., \& Storch, E. A. (2013). Clinical correlates of functional impairment in children and adolescents with obsessive-compulsive disorder. Journal of Obsessive-Compulsive and Related Disorders, 2(4), 432-436. [Link]

Nazeer, A., Latif, F., Mondal, A., Azeem, M. W., \&Greydanus, D.E. (2020). Obsessive-compulsive disorder in children and adolescents: epidemiology, diagnosis and management. Translational Pediatrics, 9(1), 76-93. [Link]

Pérez-Vigil, A., de la Cruz, L. F., Brander, G., Isomura, K., Jangmo, A., Feldman, I., ... \& Kuja-Halkola, $R$. (2018). Association of Obsessive-Compulsive Disorder with Objective Indicators of educational attainment: a Nationwide register-based sibling control study. JAMA psychiatry, 75(1), 47-55. [Link]

Petts, R. A., Duenas, J. A., \& Gaynor, S. T. (2017). Acceptance and commitment therapy for adolescent depression: Application with a diverse and predominantly socioeconomically disadvantaged sample. Journal of Contextual Behavioral Science, 6(2), 134-144. [Link]

Piacentini, J., Peris, T. S., Bergman, R. L., Chang, S., \& Jaffer, M. (2007). BRIEF REPORT: Functional impairment in childhood OCD: Development and psychometrics properties of the child obsessivecompulsive impact scale-revised (COIS-R). Journal of Clinical Child and Adolescent Psychology, 36(4), 645-653. [Link]

Pielech, M., Vowles, K. E., \& Wicksell, R. (2017). Acceptance and commitment therapy for pediatric chronic pain: Theory and application. Children, 4(2), 10. [Link]

Rezvan, S., Bahrami, F., Abedi, M., Macleod, C., Doost, H. T. N., \& Ghasemi, V. (2013). A preliminary study on the effects of attachment-based intervention on pediatric obsessive-compulsive disorder. International journal of preventive medicine, 4(1), 78. [Link]

Rezvan, S., Bahrami, F., Abedi, M., MacLeod, C., NeshatDoost, H. T. N., \& Ghasemi, V. (2012). Attachment insecurity as a predictor of obsessivecompulsive symptoms in female children. Counselling Psychology Quarterly, 25(4), 403-415. [Link]

Rozenman, M., Piacentini, J., O'Neill, J., Bergman, R.L.,Chang, S., Peris, T.S. (2019). Improvement in 
anxiety and depression symptoms following cognitive behavior therapy for pediatric obsessive compulsive disorder. Psychiatry Research, 276,115123. [Link]

Scahill, L., McDougle, C. J., Williams, S. K., Dimitropoulos, A., Aman, M. G., McCracken, J. T., ... \& Ghuman, J. (2006). Children's Yale-Brown Obsessive Compulsive Scale modified for pervasive developmental disorders. Journal of the American Academy of Child \& Adolescent Psychiatry, 45(9), 1114-1123. [Link]

Shabani, M. J., Mohsenabadi, H., Omidi, A., Lee, E. B., Twohig, M. P., Ahmadvand, A., \& Zanjani, Z. (2019). An Iranian study of group acceptance and commitment therapy versus group cognitive behavioral therapy for adolescents with obsessivecompulsive disorder on an optimal dose of selective serotonin reuptake inhibitors. Journal of ObsessiveCompulsive and Related Disorders, 22, 100440. [Link]

Siu, A. F. (2014). Effectiveness of Group Theraplay® on enhancing social skills among children with developmental disabilities. International Journal of Play Therapy, 23(4), 187. [Link]

Stewart, S. E., Ceranoglu, T. A., O'Hanley, T., \& Geller, D. A. (2005). Performance of clinician versus selfreport measures to identify obsessive-compulsive disorder in children and adolescents. Journal of Child \& Adolescent Psychopharmacology, 15(6), 956-963. [Link]

Storch, E. A., Geffken, G. R., Merlo, L. J., Mann, G., Duke, D., Munson, M., ... \& Goodman, W. K. (2007). Family-based cognitive-behavioral therapy for pediatric obsessive-compulsive disorder: Comparison of intensive and weekly approaches. Journal of the American Academy of Child \& Adolescent Psychiatry, 46(4), 469-478. [Link]

Storch, E. A., Murphy, T. K., Geffken, G. R., Soto, O., Sajid, M., Allen, P., ... \& Goodman, W. K. (2004). Psychometric evaluation of the Children's YaleBrown obsessive-compulsive scale. Psychiatry research, 129(1), 91-98. [Link]

Tayebi Naieni P, Mohammad-Khani S, Akbari M, Abedi M. (2017). The effectiveness of acceptance and commitment therapy on psychological flexibility in children with obsessive-compulsive disorder. Quarterly Journal of Child Mental Health, 4(3): 91106. (Persian). [Link]

Tompson, M. C., Langer, D. A., Hughes, J. L., \& Asarnow, J. R. (2017). Family-focused treatment for childhood depression: Model and case illustrations. Cognitive and behavioral practice, 24(3), 269-287. [Link]

Twohig, M. P. (2009). The application of acceptance and commitment therapy to obsessive-compulsive disorder. Cognitive and Behavioral Practice, 16(1), 18-28. [Link]

Van Leeuwena, W.A, van Wingena, G.A., Luytenbc, P., Denysa, D., \& van Marleade, H.J.F. (2020). Attachment in OCD: A meta-analysis. Journal of Anxiety Disorders, 70, March, 102-187. [Link]

Weir, K. N., Lee, S., Canosa, P., Rodrigues, N., McWilliams, M., \& Parker, L. (2013). Whole family theraplay: Integrating family systems theory and theraplay to treat adoptive families. Adoption Quarterly, 16(3-4), 175-200. [Link]

Yardley, J. (2012). Treatment of Pediatric ObsessiveCompulsive Disorder: Utilizing Parent-Facilitated Acceptance and Commitment Therapy. All Graduate Theses and Dissertations. 1234. [Link] 